\section{Resúmenes de los trabajos libres presentados en las XLVIII Jornadas Médico- Quirúrgicas del INER}

\author{
Neumonitis grado IV \\ secundaria a toxicidad \\ por nivolumab
}

Carla Paola Sánchez-Ríos, Mildred Ivannia Herrera-Ortega, Jorge Arturo Alexander-Alatorre, Jerónimo Rodríguez-Cid

INER Ismael Cosío Villegas

RESUMEN. Introducción: El cáncer de pulmón es la principal causa de muerte por cáncer a nivel mundial. Más de $80 \%$ son cánceres de células no pequeñas. Aunque se han producido avances significativos en el tratamiento de los subgrupos de pacientes con cáncer de pulmón, el pronóstico en la mayoría de los pacientes ha mejorado sólo modestamente. El papel emergente de la inmunoterapia con el uso de inhibidores de punto de control «check point» son opciones de tratamiento actual, que a diferencia de la quimioterapia tradicional, se dirige principalmente a las células tumorales, interfiriendo con los eventos moleculares clave en las células tumorales que impulsan el crecimiento del tumor y la invasión. Nivolumab es un anticuerpo monoclonal totalmente humano que inhibe selectivamente (PD-1) la actividad celular programada mediante la unión al receptor PD-1 para bloquear los ligandos
PD-L1 y PD-L2. Por consiguiente regula la activación y proliferación de células $\mathrm{T}$. Nivolumab ha demostrado aumentar la supervivencia de estos pacientes, utilizado en segunda línea de tratamiento. Caso clínico: Femenino de 41 años de edad. No fumadora, sin exposición a humo de leña. Diagnóstico de adenocarcinoma pulmonar de predominio lipídico mucoproductor de focos múltiples desde 2015, en tratamiento con nivolumab semanal desde el 10 de mayo 2016, 72 horas posteriores a segundo ciclo presenta astenia, adinamia, hiporexia y progresión de la disnea con aumento de requerimiento de $\mathrm{O}_{2}$ basal. TA = 121/70 mmHg; TAM = 90 mmHg; FC $=94 \mathrm{lpm} ; \mathrm{FR}=21 \mathrm{rpm} ;$ Temp $=36.7{ }^{\circ} \mathrm{C}$; $\mathrm{SpO}_{2}=86 \%$ AA. Gases arteriales: $\mathrm{pHa}=$ 7.42; $\mathrm{PaCO}_{2}=50.4 \mathrm{mmHg} ; \mathrm{PaO}_{2}=67.4$ $\mathrm{mmHg} ; \mathrm{HCO}_{3}=32.1 \mathrm{mEq} / \mathrm{L} ; \mathrm{EB}=7.5$ $\mathrm{mEq} / \mathrm{L} ; \mathrm{Lact}=0.7 \mathrm{mEq} / \mathrm{L} ; \mathrm{SaO}_{2}=91.8 \%$; $\mathrm{FiO}_{2}=43 \%$. Peso $=91.6 \mathrm{~kg}$; talla $=1.49$ $\mathrm{m} ; \mathrm{IMC}=41.2 \mathrm{~kg} / \mathrm{m}^{2}$; peso ideal $=49 \mathrm{~kg}$. Por aumento de trabajo respiratorio a las horas de su ingreso a Urgencias requirió tratamiento con VMNI modalidad CPAP después binivel por hipoventilación. Tratamiento a base de esteroides dosis altas. FBC sin complicaciones con resultados negativos para cultivos. TCAR control con disminución de vidrio deslustrado y llenado alveolar difuso. Se decide egreso por mejoría con suspensión definitiva de tratamiento anti-PD1. Discusión: Respecto a la toxicidad pulmonar se han descrito neumonitis mediada por procesos autoinmunes y neumonía organizada, dependiendo la gravedad puede requerir la interrupción del tratamiento, la terapia con corticosteroides y/o la interrupción permanente. Las neumonitis grado 2 o superior deben ser manejadas con corticosteroides dosis altas (prednisona 1-2 mg/kg al día o equivalente) seguida de dosis reducción. Hay que descartar otras etiologías de los cambios imagenológicos, principalmente de origen infeccioso. Conclusiones: Los agentes de inhibición de «check point» inmunológicos están teniendo un impacto dramático como terapia en CPCNP. El tratamiento se asocia con eventos adversos relacionados con el sistema inmunitario (irAEs) que por lo general son transitorios, pero en ocasiones pueden ser fatales. La identificación rápida de irAEs y el pronto inicio de la inmunosupresión puede optimizar los resultados. En general, el tratamiento de irAEs requiere la interrupción temporal o permanente del inhibidor de «check point» así como el uso de la inmunosupresión cuya dosis dependerá del grado de toxicidad.

\section{Cerco epidemiológico de la coccidioidomicosis asociado a casos graves de neumonía en México}

Jalil González-Valadez, ${ }^{*}$
Anjarath Lorena Higuera-Iglesias, ${ }^{*}$
María Eugenia Vázquez-Manríquez,
Gabriel Palma-Cortés, ${ }^{*}$
Carlos Cabello-Gutiérrez,
Belem Pérez-Brunet


cientes confirmados de coccidioidomicosis como casos índices y que fueran residentes. Se midió la seropositividad con la coccidioidina; se tomaron cultivos de personas sospechosos y cultivos ambientales. Se evaluaron los factores de riesgos laborales, ambientales y epidemiológicos. Se calcularon medidas de frecuencia, asociación y significancia estadística. Resultados: La muestra fue de 50 personas de la Ciudad de México. Prevalencia: $16 \%$, sexo masculino $6 \%\left(\chi^{2} 9.184 / \mathrm{p}=0.002\right)$, edad promedio 42 años (SD 16.2), 4\% visitaron área endémica $\left(\chi^{2} 3.740 / \mathrm{p}=0.05\right), 8 \%$ ocupación de riesgo $\left(\chi^{2} 13.02 / \mathrm{p}=0.00\right)$, principales comorbilidades: hipertensión arterial $(8 \% / \mathrm{p}$ $=0.44)$, diabetes mellitus $(6 \% / \mathrm{p}=0.51)$, factores de riesgo ambientales en lugar de residencia negativas. Conclusiones: En la Ciudad de México se encontró una prevalencia positiva, sin embargo, no se aisló el hongo Coccidioides en el medio ambiente relacionado con los casos positivos, por lo tanto, no cumple con las características de zona endémica. El factor de riesgo fue: ocupación y viaje a zona endémica. Se sugiere considerar a la coccidioidomicosis pulmonar en el diagnóstico diferencial de tuberculosis por ser confundida en $60 \%$.

\section{Brote con aislamiento de ácaros en expectoración en personal administrativo de un hospital}

\section{Gabriel Palma-Cortés, Jalil González-Valadez, Carlos Cabello-Gutiérrez, Anjarath Lorena Higuera-Iglesias}

INER Ismael Cosío Villegas

RESUMEN. Introducción: La OMS define al síndrome del edificio enfermo como un conjunto de enfermedades originadas por contaminación del aire en espacios cerrados. Actualmente a pesar del uso de archivos electrónicos se siguen almacenando grandes cantidades de documentos como parte de los procesos administrativos institucionales. Objetivo: Determinar las características epidemiológicas, establecer fuente y forma de transmisión, evaluar características y factores de riesgo asociados a un brote por ácaros, hongos y bacterias

en un grupo de trabajadores administrativos de un hospital. Material y métodos: Se consideró caso sospechoso a cualquier persona que labora en oficina administrativa del hospital con síntomas respiratorios, relacionados con el caso índice en el mismo período. El diagnóstico se confirmó por examen clínico, cultivos de expectoración, radiografías y espirometría. Se investigó las características clínicas, fecha, lugar, la vía y tiempo de exposición. Se tomaron muestras ambientales, se realizó examen directo con $\mathrm{KOH}$ al $10 \%$ y cultivo en agar Sabouraud, micobiótico e infusión cerebro corazón. Resultados: El brote afectó al $57 \%$ de los trabajadores relacionado con el manejo de archivo húmedo y enmohecido proveniente del sótano, el cual fue distribuido en las oficinas administrativas para su secado y consulta durante cuatro semanas a partir del 18 de enero del 2016, los síntomas fueron alérgicos, respiratorios y dermatológicos. Los cultivos de expectoración se correlacionaron con los ambientales, aislando ácaros 38\%, Aspergillus 33\%, Penicillium 24\%, Alternaria $10 \%$ y Cladosporium 5\%, Rhizomucor sólo en ambiente. Las comorbilidades reportadas: diabetes, hipertensión, cáncer, asma, embarazo, etc. Conclusiones: Los factores de riesgo a considerar en este brote con múltiples microorganismos ambientales son: asilamiento, acumulación de polvo, mala conservación de documentos, humedad e inadecuada ventilación, aunado a la falta de capacitación para manejar archivo muerto. Se destacó encontrar cultivos de expectoración con ácaros en diferentes etapas de su ciclo reproductivo y asociación con diferentes microorganismos ambientales.

\section{qPCR para el diagnóstico oportuno de HPV en pacientes con papilomatosis laríngea}

Fidencio Mejía-Nepomuceno, Víctor Hernández-Hernández, Carlos Cabello-Gutiérrez, Oscar Estrada-Camacho

INER Ismael Cosío Villegas

RESUMEN. Introducción: El cáncer cervicouterino es el cuarto cáncer más frecuente en la mujer, los cánceres de cuello y cabeza en el mundo son menos frecuentes, pero todos están relacionados con HPV de alto riesgo. En México en 2011 se registraron 5,523 cánceres de faringe causados por los anteriores. La papilomatosis es el tumor laríngeo benigno más frecuente causado por HPV de bajo riesgo, provocando papilomatosis respiratoria recurrente (RRP) que puede provocar la muerte sin generar cáncer; sin embargo, el número de recidivas por RRP no se conoce con exactitud en México, principalmente por la falta de técnicas de diagnóstico de vanguardia y económicas. Hipótesis: Si caracterizamos el HPV de manera oportuna y eficaz a los pacientes que cursan una infección de papilomatosis laríngea, entonces podremos dar un diagnóstico, para un mejor manejo de los pacientes. Objetivo: Determinar la cepa de HPV mediante qPCR en pacientes diagnosticados con papilomatosis laríngea, dar seguimiento a los pacientes y correlacionar el tipo de virus con la severidad de la enfermedad. Material y métodos: Para la extracción de ácidos nucleicos se utilizó PureLink, Viral RNA/DNA Mini kit. El qPCR se realizó con KAPA SYBR FAST qPCR kit. Se utilizaron controles de HPV de alto y bajo riesgo, para conocer la sensibilidad, especificidad y límite de detección de esta técnica. Resultados: La sensibilidad, especificidad y límite de detección de esta técnica es mejor que las técnicas de PCR punto final. Con esta técnica se está dando seguimiento a 63 pacientes del INER, infectados con HPV, siendo los subtipos HPV6 y HPV11 los más prevalentes. Conclusión: El uso de la presente técnica de qPCR como una herramienta de diagnóstico rápido y de bajo costo, es la más adecuada para el diagnóstico de pacientes en México con recursos limitados, la cual permitió conocer el subtipo viral específico dando la oportunidad de efectuar un tratamiento específico.

\section{Infección con virus de influenza H1N1 (pdm2009) en células endoteliales y su efecto sobre PAR-1}




\section{Héctor Guillermo Cordero-García, Fernando Hernández-Sánchez, Pedro Vargas-Leonor, Luis Ángel Pérez-Moreno, Carlos Cabello-Gutiérrez}

INER Ismael Cosío Villegas

RESUMEN. Introducción: El virus de influenza (IV) es considerado una emergencia sanitaria a nivel mundial; la cepa pandémica del 2009 A-H1N1 ocasionó entre 151,700 y 575,400 muertes en todo el mundo. Regularmente el virus infecta el tracto superior respiratorio, pero en casos severos puede llegar al aparato respiratorio bajo, propiciando daño a la microvasculatura pulmonar. En casos fatales se ha descrito la presencia de tormenta de citocinas y falla multiorgánica. Durante estos procesos inflamatorios el receptor activado por proteasa 1 (PAR-1) presente en el endotelio juega un papel determinante sobre la regulación de la cascada de coagulación y la inflamación tras ser activado por la trombina. PAR-1 participa en la activación de genes inflamatorios a través de las MAPK cinasas propiciando la degradación de $\operatorname{IkB} \alpha$ permitiendo la translocación de NF-kB (p65) al núcleo. Hipótesis: El virus de influenza H1N1 induce la expresión de PAR-1 en células HMEC-1. Objetivo: Evaluar el efecto de la infección por IVAH1N1-pdm2009 sobre la expresión de PAR-1 en células endoteliales HMEC-1 y su efecto sobre la degradación de $\mathrm{IkB} \alpha$ tras la estimulación con trombina. Método: Se infectaron células HMEC-1 con virus a MOI:1, o bien se estimularon con $5 \mathrm{U}$ de trombina por 1,6 y 24 horas. Se obtuvieron extractos proteícos y se realizaron ensayos de Western blot, para evaluar a las proteínas: PAR-1, p65, IkB $\alpha$ y ERK. Resultados: La infección por el virus de influenza (H1N1) mostró un incremento $(n=2)$ de los niveles de PAR-1 desde las seis horas posinfección, dicho incremento es de sólo una fracción del basal. La infección a MOI de 1 no es suficiente para degradación de $\operatorname{IkB} \alpha$ a tiempos cortos, pero sí promueve su descenso a las 24 horas. Conclusiones: La infección aumenta la presencia de PAR-1 que podría estar relacionado con la actividad de la vía de NFkB.
El virus de influenza A afecta la expresión de trombomodulina en células endoteliales

Pedro Vargas-Leonor, Fernando Hernández-Sánchez, Héctor Guillermo Cordero-García, Luis Ángel PérezMoreno, Carlos Cabello-Gutiérrez

INER Ismael Cosío Villegas

RESUMEN. Introducción: El endotelio vascular es el tejido encargado de regular los procesos hemostáticos al modular la actividad de la trombina circulante mediante la expresión de moléculas procoagulantes como el factor tisular o moléculas anticoagulantes como la trombomodulina (TM). Ya se ha comprobado que en pacientes infectados con el virus de influenza que cursan con cuadros clínicos severos se presenta una inflamación exacerbada y un desequilibrio en los procesos de trombosis vascular, pero no se ha esclarecido el papel del endotelio en estos casos. Hipótesis: El virus de influenza disminuye la expresión de TM en células endoteliales. Objetivo: Evaluar si la infección de células endoteliales HMEC-1 con el virus de influenza A H1N1-pdm09 modifica la expresión de TM a nivel transcripcional o traduccional. Material y métodos: Se obtuvieron extractos proteicos totales y RNA total a partir de células HMEC-1 infectadas con el virus de influenza A H1N1-pdm09. La expresión del gen para TM y la expresión de proteínas virales se evaluó mediante qPCR o PCR de punto final. La abundancia relativa de la TM se analizó por Western blot usando beta-actina como control de carga. Resultados: El virus de influenza es capaz de promover la disminución de la expresión de TM a nivel proteico a las seis horas posinfección, efecto que permanece hasta las 24 horas. Este mismo efecto de disminución se pudo detectar a nivel de la expresión del gen en los mismos tiempos de infección en concordancia con el efecto ya reportado para TNF- $\alpha$. La disminución de la TM coincidió con el aumento de la expresión de genes virales. Conclusión: La infección de células endoteliales por el virus de influenza A afecta la expresión de TM. Este efecto promovido por el virus podría favorecer la desregulación de los procesos coagulación e inflamación.

\section{Las pruebas \\ inmunoserológicas son una herramienta importante en el diagnóstico de enfermedades micóticas}

\section{Elba Lucía Valencia-Maqueda, Gabriel Palma-Cortés, Carlos Cabello-Gutiérrez}

INER Ismael Cosío Villegas

RESUMEN. Introducción: Las micosis invasoras son cada vez más frecuentes causadas por un grupo heterogéneo de hongos, afectando a sujetos con grados variables de inmunocompromiso, son cuadros difíciles de reconocer ya que los síntomas y cuadros son inespecíficos. El diagnóstico de las micosis se realiza mediante examen médico, radiológico y de laboratorio (examen directo, cultivo, histología y pruebas inmunoserológicas, entre otras). Material y métodos: Se analizó el total de pruebas serológicas efectuadas durante 2001 a 2015 en el Departamento de Investigación en Virología y Micología del INER. Pruebas realizadas: inmunoprecipitación en tubo capilar y doble inmunodifusión en gel de Ouchterlony para detección de anticuerpos contra Coccidioides spp., Histoplasma capsulatum y Aspergillus mezcla de (flavus, niger y fumigatus). Resultados: Se realizaron un total de 793 pruebas serológicas. De las cuales un $11 \%$ fueron positivas para Coccidioides spp., $18 \%$ positivas para Aspergillus spp. y $10 \%$ para Histoplasma capsulatum. El promedio de edad fue de dos meses hasta 80 años, se realizaron las pruebas a $56.11 \%$ hombres y a $43.89 \%$ mujeres. Discusión: Por lo general las micosis no son consideradas en pacientes sintomáticos con enfermedad pulmonar debido a su similitud con la tuberculosis, enfermedad endémica en nuestro país. Las enfermedades micóticas se encuentran distribuidas ampliamente a nivel mundial dando origen a la enfermedad clínicamente manifiesta. Es por ello que las pruebas de laboratorio 
constituyen una valiosa ayuda para establecer un diagnóstico diferencial en los pacientes. Conclusiones: Los antígenos crudos son de bajo costo, fácil manejo y de rápida producción; son ideales para la detección de anticuerpos en estudios generales, para establecer diagnósticos más rápidos. El INER es una institución donde se concentran pacientes con afecciones pulmonares crónicas muy variadas incluyendo diferentes tipos de micosis, por lo que es de gran interés conocer la frecuencia de estas enfermedades apoyándose en herramientas alternas al cultivo.

\section{Osteocondroma mediastinal. Presentación de caso y revisión de la literatura}

\section{Carla Paola Sánchez-Ríos, John Eduardo Bastidas-Meza, Lucy Annetty Marcano-de la Rosa, Miguel Ángel Olaiz-Hernández}

INER Ismael Cosío Villegas

RESUMEN. Introducción: Los osteocondromas son lesiones benignas formadoras de cartílago. Su patogenia es oscura. Son lesiones compuestas de hueso medular y cortical recubierta de una capa de cartílago hialino. La presentación en costilla y esternón es extremadamente rara. Caso clínico: Hombre de 30 años. Disnea de esfuerzo progresiva de dos años. Imagen radiográfica y tomográfica de lesión ocupativa en hemitórax izquierdo. Se realiza resección quirúrgica con resultado histopatológico de osteocondroma. Discusión: Los osteocondromas son anomalías benignas, frecuentemente asintomáticos. Se documentan como hallazgos en estudios de imagen realizados por otra causa. Presentan síntomas de complicaciones tales como fracturas, compresión medular, entre otras. El diagnóstico diferencial de las lesiones de costilla son encodroma, osteoblastomas, osteoma osteoide, condroblastoma, hemangioma y el condrosarcoma. Conclusión: La presentación costal de los osteocondromas es extremadamente rara. Consideramos de interés la presentación de reportes de casos para ampliar la literatura.

Oclusión exitosa de malformación arteriovenosa como causa de neumonía postobstructiva

\section{Carla Paola Sánchez-Ríos, Gerardo Rodríguez-Mendoza, Enrique Baltazares-Lipp}

INER Ismael Cosío Villegas

RESUMEN. Introducción: Las malformaciones arteriovenosas pulmonares son comunicaciones anormales entre el sistema arterial y venoso. Clínicamente se puede manifestar con cianosis y disnea, hemoptisis por roturas en bronquios, hemotórax o embolias paradójicas. Su diagnóstico se confirma con TC, RM o angiografía digital. Caso clínico: Mujer de 36 años con disnea de esfuerzo de dos meses, fiebre, hemoptisis intermitente y dolor pleurítico. Imagen área sugestiva de MAV y neumonía. Se inicia antibioticoterapia así como angiografía en TAP y rama inferior derecha para oclusión de MAV. Se colocan coils interlock con oclusión exitosa. Discusión: Ante la sospecha clínica de MAV se debe objetivar el shunt que en nuestro caso se descartó. Se recomienda tratamiento en las MAV sintomáticas o mayores de $3 \mathrm{~mm}$. Los avances tecnológicos con coils han mostrado buenos resultados. Conclusión: Las MAV con frecuencia se encuentran en lóbulos inferiores. En nuestro caso se ofrece tratamiento con coils resultando exitoso.

\section{Cáncer pulmonar epidermoide, reporte de serie de casos} Mariana Fragoso-Mejía, Norma
Angélica Téllez-Navarrete, Uriel
Rumbo-Nava, Renata Báez-Saldaña

INER Ismael Cosío Villegas

RESUMEN. Introducción: El cáncer pulmonar epidermoide representa el $30 \%$ de todos los casos de cáncer pulmonar. Muestra un patrón de crecimiento relativamente lento y por lo común de localización central. Se manifiesta como atelectasias obstructivas o neumonías y hemoptisis. Objetivo: Conocer las características demográficas y clínicas de pacientes con diagnóstico de cáncer pulmonar epidermoide del Instituto $\mathrm{Na}$ cional de Enfermedades Respiratorias. Material y métodos: En este trabajo realizamos una revisión de expedientes del Archivo Clínico del INER en el período de enero 2104 a diciembre 2015. El análisis de datos fue realizado en el sistema SPSS v20. Resultados: Se revisaron 27 casos de pacientes con diagnóstico de cáncer pulmonar epidermoide, 20 (74\%) hombres, H:M 2.8:1, la media de edad fue de $65 \pm 10.5$ años. El $74 \%$ (20) con tabaquismo y la media del índice tabáquico fue de 51 paquetes/año (12-110). El $37 \%$ (10) tenía antecedente de cáncer en algún familiar y de esto, el cáncer gástrico fue más frecuente $14.8 \%$ (4). El método diagnóstico que más se utilizó fue la broncoscopia $74.1 \%$ (20), posteriormente toracoscopia 4 (14\%), biopsia guiada por imagen (TAC) $1(3.7 \%)$ y $2(7.4 \%)$ casos por pieza quirúrgica. En el $29 \%$ (8) de los casos se observó derrame pleural. Las metástasis se observaron en el $44 \%$ (12) de las cuales 7 (26\%) óseas, 2 (7.4\%) SNC y 2 (7.4\%) pleura. Sólo el 67\% (18) de los casos tuvo seguimiento y recibió tratamiento en el INER: 16 con quimioterapia, 2 radioterapia y 2 lobectomía. El 26\% (7) de los pacientes fallecieron en hospitalización, las causas de muerte fueron: 2 (28\%) hemoptisis masiva y 5 (70\%) neumonía postobstructiva. Conclusiones: El cáncer pulmonar epidermoide representa el $17 \%$ de los tipos de cáncer pulmonar en el INER. Es importante conocer la presentación y desenlace para un mejor seguimiento de los pacientes; existe un porcentaje importante de complicaciones hospitalarias y el $36 \%$ pierde seguimiento.

\section{Caracterización}

tomográfica del involucro

pulmonar y evaluación

del período de latencia

en papilomatosis

laringotraqueal 


\begin{abstract}
Aloisia Paloma-Hernández, María Alejandra Espinoza-Barillas, Lya Edith Pensado-Piedra, Fortunato JuárezHernández, Roberto Sotelo-Robledo
\end{abstract}

INER Ismael Cosío Villegas

RESUMEN. Introducción: La papilomatosis laríngea recurrente es una enfermedad crónica caracterizada por la presencia de lesiones benignas exofíticas en el tracto respiratorio superior. La diseminación pulmonar es poco frecuente, la frecuencia reportada en la literatura oscila entre el 1 y $4 \%$, pero cuando ocurre nos indica gravedad de la enfermedad ya que se asocia a peor pronóstico y mayor probabilidad de malignización. El agente etiológico de la enfermedad es el virus del papiloma humano. Los serotipos implicados en la papilomatosis laríngea son el 6 y el 11, responsables también de los condilomas genitales. Objetivos: Describir los hallazgos tomográficos de las lesiones pulmonares de papilomatosis laringotraqueal y determinar período de latencia entre el diagnóstico y la aparición de las lesiones pulmonares visibles por tomografía. Material y métodos: Estudio retrospectivo, retrolectivo, descriptivo, de corte transversal en el período comprendido entre el 2010 al 2015. El universo lo conformaron 95 pacientes con diagnóstico de papilomatosis laringotraqueal. Resultados: La prevalencia de involucro pulmonar de papilomatosis laringotraqueal fue de del 9\% (9 pacientes); 5 mujeres, 4 varones. El diagnóstico clínico se realizó en la edad pediátrica a excepción de un paciente. El $99 \%$ de los pacientes tienen antecedente de múltiples broncoscopias, resecciones de papilomas traqueales y/o broncoscopia. La presentación tomográfica en el $100 \%$ de los pacientes fue el patrón multinodular cavitado con distribución multilobar, no se identificó procesos neumónicos postobstructivos y/o atelectasias en ninguno de los pacientes. La prevalencia de malignización fue del $11 \%$, ya que uno de los pacientes desarrolló carcinoma epidermoide. En todos los pacientes las lesiones en parénquima pulmonar aparecieron varios años después del diagnóstico clínico. Conclusiones: El patrón tomográfico de la papilomatosis laringotraqueal con afectación de parén- quima pulmonar en una serie de nueve pacientes es el patrón multinodular cavitado y estas lesiones aparecen años después del diagnóstico clínico.

\section{Efecto Macklin secundario a influenza a H3N2}

Luisa Fernanda MartínezValdeavellano, María del Carmen Castillo-Villatoro, Margarita SalcedoChávez, José Roberto VelázquezSerratos, Alejandro Alejandre-García, Teresa Leal-Arriaga

INER Ismael Cosío Villegas

RESUMEN. Introducción: El neumomediastino espontáneo es una entidad rara con una incidencia de 1/800 en cirugía torácica, hasta 1/44,000 en urgencia. Es provocado por cualquier situación que desarrolle maniobra de Valsalva. Se ha asociado con infección (43\%) 1. A la visualización tomográfica de aire en las vainas perivasculares y peribronquiales se le denomina efecto Macklin. 2. Objetivo: Describir el caso y abordaje de una paciente con efecto Macklin por influenza H3N2. Presentación de caso: Femenino de 12 años, previamente sana. Dos semanas previo a consultar presenta tos, la cual se exacerba y se asocia con dolor torácico. Refiere impacto en tórax por compañero de escuela. Se agrega fiebre, dificultad respiratoria y cianosis. Al ingreso: FC 120 lpm, FR 50 rpm, $\mathrm{SpO}_{2} 21 \%$ 51\%, afebril, datos de dificultad respiratoria, enfisema subcutáneo paraesternal derecho, sibilancias bifásicas bilaterales. Ingresa a UTIP, manejo con ceftriaxona, claritromicina, oseltamivir, esteroide sistémico, aminofilina, nebulizaciones y oxígeno. Se coloca catéter venoso central, presenta neumotórax derecho y se coloca sonda endopleural. Al octavo día con deterioro clínico posterior a esfuerzo realizado (aumenta enfisema subcutáneo); se escala tratamiento: piperacilina-tazobactam. Se realiza broncoscopia reportando cambios inflamatorios; TAC que reporta efecto Macklin. Paciente con mejoría, se da alta con esteroide inhalado. Resultado de PCR positivo para influenza A H3N2. En seguimiento con rehabilitación pulmonar, indicación de limitación de actividad física. Discusión: El neumomediastino espontáneo o enfisema mediastinal es provocado por eventos que produzcan aumento de la presión de la vía aérea. Asociado con procesos infecciosos, se reportan dos casos asociados a influenza H1N1.3 En la paciente se documenta influenza $\mathrm{H} 3 \mathrm{~N} 2$ y posteriormente presenta deterioro secundario a maniobra de Valsalva realizada. Conclusiones: El neumomediastino espontáneo y el efecto Macklin son entidades raras, autolimitadas, causadas por diferentes patologías, desde el esfuerzo realizado por actividad física, traumatismos, crisis asmáticas $(0.3 \%)$ o infecciones (43\%). El tratamiento es sintomático, reposo y oxígeno suplementario.

\section{Microbiología de la infección pleural mediante el cultivo en medio de transporte para hemocultivo}

\section{Alejandro Marín Castañeda-Barón, Alejandra Renata Báez-Saldaña, Ángel Emmanuel Vega-Sánchez}

INER Ismael Cosío Villegas

RESUMEN. La microbiología del derrame pleural para neumónico en México es poco conocida, esto debido a la mala calidad de la manipulación de las muestras, así como su oportuna entrega al laboratorio de destino, entre otras. El contar con medios de transporte en el cual el factor tiempo no se vea involucrado puede ayudarnos a caracterizar las etiologías infecciosas de los derrames pleurales para neumónicos en nuestro país. Métodos: Se recolectaron pacientes de enero de 2016 al 31 de julio de 2016 con el diagnóstico de derrame pleural infeccioso, se inoculó $10 \mathrm{~mL}$ de líquido en medio para hemocultivo piógenos, $10 \mathrm{~mL}$ en medio para hemocultivo de micobacterias y $10 \mathrm{~mL}$ en medio estándar para comprar entre ellos el número de aislamiento. Resultados: Se incluyeron 29 pacientes, el aislamiento en medio para hemocultivo piógenos, micobacterias y medio estándar fue 41, 37 y 31\%, respectivamente. Conclusión: El 
transporte de líquido pleural infeccioso en medio para hemocultivo es comparable e incluso mejor que el medio estándar en la detección de patógenos bacterianos en el espacio pleural.

\section{Mesotelioma epitelioide metastásico a mama. Reporte de un caso}

\section{Edgar Alejandro Reyes-García, Arturo Coyt-Mendoza, Luis Joel Arroyo-Hernández, Miguel Ángel Olaiz-Hernández, José Felipe Torreblanca-Corona, Uriel Rumbo- Nava, Renata Báez-Saldaña}

INER Ismael Cosío Villegas

RESUMEN. Introducción: El mesotelioma pleural maligno es una neoplasia insidiosa debido a su largo período de latencia de hasta 40 años posterior a exposición a amianto. En el $80 \%$ de los casos hay una relación causa-efecto con exposición laboral a asbesto. La incidencia es de 20 casos por millón/año. La presentación clínica más común es derrame pleural maligno con características: exudado, serohemático, predominio linfocítico, $\mathrm{pH}<7.30$, glucosa normal. El citológico presenta predominio linfocítico con relación linfocitos/PMN > 75\% y reacción mesotelial $>5 \%$. La TAC tórax contrastada es el estudio de elección para abordaje diagnóstico que demuestran: engrosamiento pleural irregular o nodular $>1 \mathrm{~cm}$, engrosamiento pleural mediastinal, afectación de cisuras interlobares. El diagnóstico es histopatológico. Los marcadores de inmunohistoquímica más utilizados son: calretinina, WT-1, queratinas CK5/CK6. El tipo histológico más común es epitelioide, sarcomatoide y bifásico. Los sitios de metástasis más comunes: contigüidad a pared torácica, diafragma, mediastino contralateral y pulmón. Objetivo: Descripción de caso clínico de mesotelioma epitelioide con metástasis a mama. Material y métodos: Estudio descriptivo. Reporte de caso clínico. Resultados: Mujer de 48 años, antecedentes: exposición a humo de leña 20 años. Hipertensión arterial 8 años de evolución. Inicia padecimiento en noviembre de 2015; tos no productiva, pérdida ponderal $8 \mathrm{~kg}$, dolor torácico izquierdo. Acude a hospital general, ingresa por derrame pleural izquierdo masivo, estancia 27 días, sin mejoría clínica, egresa voluntariamente. 04.05 INER. Derrame pleural izquierdo masivo. Toracocentesis; serohemático, PT 3.2, LDH 1544, linfocitos 95\%, pH 6.9. 24.05 biopsia pleural toracoscopia. Reporte de patología: mesotelioma epitelioide, inmunohistoquímica: positivos WT1 $(+++)$, calretinina (+). Negativos TTF1. Estancia pabellón 3: masa palpable en mama izquierda, características: pétrea, adherida planos profundos, no móvil. USG mamario: imagen ovoide, ecogénica, heterogénea, $22 \times 14 \times 16 \mathrm{~mm}$, bordes mal definidos. Mastografía 05.06.16. Reporte: BI-RADS IV. Biopsia guiada USG: RHP mesotelioma epitelioide infiltrante de mama. Inmunohistoquímica calretinina (+/+++), TTF-1, napsin A, CK 7, MOC 31, CK 5/6, WT-1 negativos. Receptores de estrógeno y progesterona negativos. Valorada por oncología, diagnóstico de egreso: mesotelioma epitelioide EV IV con metástasis a mama derecha. Conclusión: La inmunohistoquímica es una herramienta importante en el diagnóstico diferencial de mesotelioma pleural maligno así como de sus metástasis.

\section{Sarcoma sinovial bifásico. A propósito de un caso \\ Óscar Gabriel Jiménez-Cabrera, José Omar Barreto-García, Carlos Damián Zárate-Dávila, César Luna-Rivero}

INER Ismael Cosío Villegas

RESUMEN. Introducción: Se ha descrito la presencia de sarcoma sinovial en múltiples localizaciones. Es extremadamente raro, constituye entre 0.1 y $0.5 \%$ de todas las neoplasias de pulmón, con características clínicas, morfológicas y genéticas específicas. Presenta predilección por la región paraarticular de las extremidades inferiores en adolescentes y adultos jóvenes. El análisis molecular no es requerido para realizar el diagnóstico de acuerdo con la OMS. Metodología:
Estudio descriptivo de un caso clínico. Con datos recuperados del expediente clínico. Resultados: En un paciente de la segunda década de la vida sin antecedente de enfermedad oncológica o algún factor de riesgo para desarrollar la misma. Dx biopsia de pleura con reacciones de inmunohistoquímica resultando: positivas: CK AE1/AE3, Bcl2, EMA, CD56, vimentina, CD99. Conclusiones: Los sarcomas sinoviales pulmonares por lo común aparecen en localizaciones periféricas, bien circunscritas pero no encapsuladas. Son infrecuentes. Tienen componentes fusiformes y epiteliales. El pronóstico para los pacientes con sarcoma sinovial pulmonar es pobre, con una tasa general de supervivencia a los cinco años de $50 \%$. Los factores que predicen un peor pronóstico en pacientes con sarcomas sinoviales son: el tamaño del tumor ( $>5 \mathrm{~cm})$, sexo masculino, edad avanzada ( $>20$ años), necrosis tumoral extensa, grado histológico, cantidad de mitosis ( $>10$ por campo de alto poder), la invasión neurovascular $\mathrm{y}$, recientemente agregado, el SYT-SSX1. No existe un consenso para el tratamiento de estos tumores debido a que se presentan de manera muy infrecuente.

\section{Neumotórax espontáneo como manifestación inicial del complejo esclerosis tuberosa- linfangioleiomiomatosis}

\section{Carla Paola Sánchez-Ríos, Mónica Sarai Rodríguez-Rodríguez}

INER Ismael Cosío Villegas

RESUMEN. Introducción: El complejo esclerosis tuberosa (CET) es una enfermedad de patrón autosómico dominante de afectación multisistémica, caracterizada por el crecimiento de hamartomas. A nivel pulmonar su principal manifestación es la linfangioleiomiomatosis (LAM). La LAM es una enfermedad que afecta predominantemente a la mujer fértil que se caracteriza por una proliferación anormal de células musculares lisas inmaduras (células LAM), crecen de manera aberrante en la vía aérea, parénquima, linfáticos y 
vasos sanguíneos pulmonares. Los tres hallazgos clínicos más frecuentes son la disnea, el neumotórax y la tos. La disnea es de establecimiento lento y progresivo. El neumotórax es el suceso centinela que orienta al diagnóstico. Su incidencia varía entre el 39 y $81 \%$, siendo característico la recidiva reportada hasta en $80 \%$. La edad media de las pacientes en el momento del diagnóstico está en torno a los 35 años. El diagnóstico de LAM requiere una TCAR $\mathrm{y}$, por otro lado, una biopsia positiva que incluya estudio inmunohistoquímico con HMB-45 o un contexto clínico compatible. Caso clínico: Femenino de 44 años de edad, antecedentes familiares de esclerosis tuberosa (hija y hermano), diagnóstico de esclerosis tuberosa (epilepsia) desde la infancia en tratamiento irregular con carbamazepina. Acude con cuadro clínico de un mes de evolución caracterizado por disnea de medianos esfuerzos, tos seca y dolor torácico. Exploración física con vitalografía normal, saturación $94 \%$. Consciente, orientada, con retraso mental leve por minimental de 18/30 fallando en memoria, atención, praxia constructiva, con adecuado lenguaje, movilización espontánea de extremidades. Angiofibroma facial izquierdo, manchas café con leche en dorso y fibromas digitales. Tórax ectomórfico asimétrico ruidos respiratorios disminuidos en base derecha. Abdomen globoso a expensas de tumoraciones no móviles no dolorosas de consistencia pétrea de manera bilateral en flancos. Se mantuvo en vigilancia, recibió terapia de rehabilitación como única oferta terapéutica posible y se egresó con recomendaciones generales por máximo beneficio. Discusión: La LAM es una enfermedad cuya presentación más frecuente es asociada al complejo de esclerosis tuberosa. No existe en la actualidad ningún tratamiento curativo. El tratamiento con progesterona y el trasplante pulmonar han sido controvertidos. Recién se están ensayando agentes como los inhibidores de la Rheb, antagonistas selectivos de estrógenos, inhibidores de la tirosinkinasa, inhibidores de las MMP, inhibidores de la angiogénesis e inhibidores de la linfangiogénesis. El curso de la enfermedad es ampliamente variable y no se conocen factores pronósticos relevantes. El dete- rioro del intercambio gaseoso es el factor más importante que agrava el pronóstico. Gran parte de esta variabilidad durante el curso de la enfermedad podría explicarse por el polimorfismo genético. Conclusión: Tomando la línea de investigación entre la asociación de CET y LAM así como las recomendaciones de tamizaje de patología pulmonar asociada en pacientes mayores de 18 años con diagnóstico de CET, se pretende un diagnóstico de la afección pulmonar de manera temprana. Así, junto con la buena práctica preventiva y el reporte de casos similares a éste, intentaremos concientizar la importancia del diagnóstico oportuno para tratar de proporcionar terapéuticas encaminadas a disminuir la morbimortalidad, mejorar el pronóstico y sobre todo, la calidad de vida de estos pacientes.

\section{Expresión de la $\beta$-defensina-2 en pacientes con infecciones virales y crisis de asma}

Dora Patricia Rosete-Olvera, Christian Trejo-Jasso, Carlos CabelloGutiérrez, Ignacio Páramo-Ramírez, Rocío Chapela-Mendoza, José Luis Sandoval-Gutiérrez

INER Ismael Cosío Villegas

RESUMEN. Introducción: El asma es una enfermedad obstructiva crónica que se caracteriza por obstrucción, hiperreactividad e inflamación. Las infecciones respiratorias virales son la principal causa de las exacerbaciones o crisis de asma. La $\beta$-defensina- 2 es un péptido catiónico con actividad antiviral, forma parte de la inmunidad innata y se expresa en el epitelio respiratorio en respuesta a infecciones, procesos inflamatorios y citocinas proinflamatorias. Recién se le atribuye la propiedad de modular la respuesta inmune innata y adaptativa. Hipótesis: $\mathrm{Si}$ la expresión de la $\beta$-defensina- 2 aumenta en pacientes con crisis de asma e infección viral, entonces la $\beta$-defensina- 2 puede estar causando las crisis. Objetivo: Determinar la expresión de la $\beta$-defensina- 2 en pacientes con crisis y sin crisis de asma y relacionar su expresión con la infección viral y la crisis de asma. Material y métodos: Se estudiaron pacientes adultos con crisis de asma y pacientes con asma sin crisis. Se les midió la función pulmonar $\left(\mathrm{FEV}_{1}\right)$ y en células nasofaríngeas se identificaron virus respiratorios y $\beta$-defensina- 2 por RT-PCR. En sangre se cuantificaron las células inflamatorias y se midió IgE total y $\beta$-defensina- 2 por ELISA. Resultados: 25 pacientes adultos con crisis de asma y 36 pacientes sin crisis de asma fueron estudiados. Los pacientes con crisis presentaron infección viral $(92 \%)$ y el virus de influenza A $(88 \%)$ fue el más frecuente. La $\beta$-defensina- 2 se expresó en pacientes con crisis $(56 \%)$ y sin crisis (67\%). La concentración máxima de $\beta$-defensina- 2 en suero de los pacientes con crisis fue de $58,026.5 \mathrm{pg} / \mathrm{mL}$ y en los pacientes sin crisis fue de $24,823.5$ pg/mL. Conclusiones: La $\beta$-defensina- 2 se expresó en células epiteliales y suero en los pacientes con crisis y sin crisis de asma, no hay diferencias estadísticas significativas. Sin embargo, se observó que en los pacientes con crisis de asma las concentraciones de $\beta$-defensina- 2 son mayores.

\section{Capilaroscopia y angiogénesis en enfermedades autoinmunes sistémicas}

Alfonso Rafael Salgado-Aguayo, Mercedes Pinto-Ortiz, Felipe Mendoza-Pérez, Daniel Paz-Gómez, María del Carmen Navarro-González

INER Ismael Cosío Villegas

RESUMEN. Antecedentes: En enfermedades autoinmunes sistémicas (EAS), cambios en la microvasculatura pueden afectar la fisiopatogénesis. Procesos inflamatorios promueven la angiogénesis, cuya regulación es controlada en parte por factores solubles. A la fecha no se ha descrito una correlación entre estas proteínas y los cambios vasculares en EAS. Los cambios vasculares de vasos pequeños se pueden medir mediante capilaroscopia en el lecho ungueal, una prueba no invasiva y fácil de realizar. Hipótesis: Los cambios en la producción de factores angiogénicos/ 
angiostáticos influyen en el desarrollo de las alteraciones vasculares observadas en EAS. Objetivos: Analizar cambios vasculares en lecho sanguíneo pequeño por medio de capilaroscopia ungueal y determinar niveles de factores angiogénicos en suero de pacientes con EAS. Correlacionar niveles de factores angiogénicos y angiostáticos con las alteraciones de capilares de pacientes con EAS. Material y métodos: Se incluyeron 10 pacientes con diagnóstico de EAS que acudieron a la consulta de reumatología; a todos ellos se les realizó historia clínica completa e historia reumatológica, y se les realizó capilaroscopia del lecho ungueal de todos los dedos de las manos. Las imágenes fueron evaluadas posteriormente por un especialista cegado a la identidad del paciente. De cada paciente se obtuvieron $6 \mathrm{~mL}$ de sangre periférica por punción venosa en tubos sin anticoagulante. El suero se usó para determinar niveles de VEGF, PDGF-BB, IL-8, G-CSF, PECAM-1, HGF, leptina, angiopoyetina y folistatina, empleando un kit Luminex (Hu Angio Kit, BioRad, CA USA). Resultados: Todos los pacientes tuvieron cambios vasculares evidenciados por capilaroscopia (tortuosidad, adelgazamiento, amputación o formación aneurismática). Niveles anormales de PDGF-BB se asociaron con mayor tortuosidad de los capilares. Existen cambios $(p>0.05)$ en niveles de factores angiogénicos (angiopoietina, folistatina, IL-8 y HGF) en pacientes con EAS. Conclusiones: Los resultados obtenidos sugieren que cambios en niveles de factores angiogénicos influyen en el desarrollo de las alteraciones observadas por capilaroscopia en EAS.

\section{Efecto antialérgico de 6-hidroxiflavona en un modelo de asma en el cobayo}

Angélica Flores-Flores, * Blanca Margarita Bazán-Perkins, ${ }^{\ddagger}$ Samuel Enoch Estrada-Soto, * Alexis Raynet-Montesinos, ${ }^{*}$ Silvia Fernanda Clorio-Guerrero ${ }^{\S}$

*Universidad Autónoma del Estado de MoreIos; 抽ER Ismael Cosío Villegas; §UNAM
RESUMEN. Los flavonoides son miembros de una familia de metabolitos secundarios polifenólicos presentes de manera abundante en plantas, han reportado potencial terapéutico como antioxidante, inflamatorio así como alérgico, hepatotóxico, entre otros. La 6-hidroxiflavona (6-OHF) ha mostrado efectos relajantes en el músculo liso traqueal de la rata, aún se desconoce su mecanismo de acción. Objetivo: Determinar la toxicidad de la 6-OHF y su posible mecanismo de acción en la contracción del músculo liso de las vías aéreas. La evaluación de la toxicidad aguda y subcrónica así como perfil bioquímico de la 6-OHF en ratones CD1 no mostró ningún tipo de daño en órganos, ni alteraciones en parámetros bioquímicos. Al determinar algunas propiedades fisicoquímicas como el área superficial polar y el Log P, se diseñó un farmacóforo con las características mínimas necesarias, 6-OHF cumplió con estas características, lo que nos sugiere que este fármaco podría ser un traqueo relajante y posible bloqueador de canales de calcio en el músculo liso. Para evaluar esta hipótesis, sensibilizamos a un antígeno (ovoalbúmina, OVA) cobayos machos HsdPoc:DH y 15 días después se evaluó la reactividad de las vías aéreas a la histamina así como la broncoobstrucción por OVA. A algunos cobayos se les administró por vía intraperitoneal 45 minutos antes del reto con OVA, 6-OHF con las siguientes dosis 89.28, 50 y 28 $\mathrm{mg} / \mathrm{kg}$, utilizando como vehículo propilenglicol al $10 \%$. Cada grupo formado por seis cobayos. Observamos que 6-OHF no alteró la magnitud de la hiperreactividad a la histamina; sin embargo, la administración de $50 \mathrm{mg} / \mathrm{kg}$ de 6-OHF disminuyó la broncoobstrucción inducida por OVA en comparación al grupo control. Conclusión: Los datos sugieren que 6-OHF posiblemente no está alterando la contractilidad del músculo liso de las vías aéreas, pero sorpresivamente la 6-OHF parece tener efectos antialérgicos que pudiesen coadyuvar en el tratamiento del asma alérgica.

\section{Hemangiomatosis capilar pulmonar. Reporte de caso y revisión de la literatura}

Carla Paola Sánchez-Ríos, Olivia Sánchez-Cabral, Miguelina JáquezCarrasco, Berenice López-González, Iván Rodolfo García-Izquierdo

INER Ismael Cosío Villegas

RESUMEN. Introducción: La hemangiomatosis capilar pulmonar (HCP) es una enfermedad, afecta entre los $20 \mathrm{y}$ 40 años. Se reporta una incidencia de 4/1,000,000. Muestra afección bilateral en etapas iniciales asintomática y en etapas avanzadas progresa a cor pulmonale. La supervivencia media es de tres años culminando finalmente en colapso cardíaco. Caso clínico: Hombre de 36 años, dos meses con disnea progresiva, tos seca y sibilancias. TAC tórax simple evidencia patrón vidrio deslustrado. FBC con EBUS-R encontrando múltiples lesiones polipoides en todo el árbol bronquial de manera bilateral con invasión de cartílago de la vía aérea. Resultado histopatológico: hemangioma capilar. Discusión: En la HCP la proliferación capilar que llena los septos alveolares interrumpe el mecanismo de intercambio gaseoso disminuyendo la difusión pulmonar de monóxido de carbono. Conclusiones: La $\mathrm{HCP}$ es una enfermedad rara y benigna, pero con desenlace mortal. Se han descrito trasplantes pulmonares o cardiopulmonar como únicos tratamientos definitivos.

\section{Incremento de proteasas durante la crisis de asma genera diferentes tipos de integrinas solubles}

Olivia Téllez-Jiménez, ${ }^{\star}$ Patricia Ramos-Ramírez, ${ }^{\text {Rocío Chapela- }}$ Mendoza, * Ignacio Páramo-Ramírez,* Christian Trejo-Jasso, * Erika LópezEstrada, ${ }^{*}$ José Luis Miguel-Reyes*

*INER Ismael Cosío Villegas; ‡KRC

RESUMEN. La crisis de asma es un episodio caracterizado por un incremento de los síntomas respiratorios y una disminución importante en la función pulmonar. En un estudio previo en un modelo crónico de asma en cobayo y en pacientes con asma observamos un incremento significativo de 
los niveles de las integrinas $\alpha 1 \beta 1$ y $\alpha 2 \beta 1$ y de la subunidad $\beta 2$ de integrina solubles en suero, ignoramos si durante la crisis de asma estos niveles pueden modificarse. Nuestro objetivo fue evaluar los niveles séricos de estas integrinas en pacientes con crisis de asma y posibles proteasas involucradas en el corte proteolítico de integrinas. Se reclutaron pacientes con y sin crisis de asma $(n=26$ y 21 , respectivamente) y voluntarios sanos $(n=29)$. Determinamos en suero los niveles de integrinas $\alpha 1 \beta 1, \alpha 2 \beta 1$, subunidad $\beta 2$ de integrina, colágena I, ADAM10 y MMP9 mediante ELISA y Western blot. Los niveles de las integrinas $\alpha 1 \beta 1$ y $\alpha 2 \beta 1$ así como de la subunidad $\beta 2$ de integrina aumentaron en pacientes sin crisis asmática en comparación con los controles $(\mathrm{p}<0.05)$. El incremento de los niveles de la integrina $\alpha 2 \beta 1$ y la subunidad $\beta 2$ de integrina se mantuvieron en pacientes con crisis de asma; sin embargo, los niveles de la integrina $\alpha 1 \beta 1$ disminuyeron en pacientes con crisis asmática en comparación con los pacientes sin crisis y los voluntarios sanos ( $\mathrm{p}<0.01$ y $\mathrm{p}<0.001$, respectivamente). Los niveles séricos de colágena I no se modificaron; mientras que los niveles de ADAM10 y MMP9 aumentaron sólo en los pacientes con crisis de asma. Estos resultados sugieren que durante la crisis de asma los altos niveles de ADAM10 y MMP9 podrían estar involucrados con el incremento de la integrina $\alpha 2 \beta 1$ y la subunidad $\beta 2$ de integrina solubles. Es probable que los mecanismos que liberan a la integrina $\alpha 1 \beta 1$ no se activen durante la crisis de asma.

\section{Experiencia de 6 meses} del programa EPID-INMUJERES en el Instituto Nacional de Enfermedades Respiratorias

\section{Karen Pamela Martínez-Espinosa, ${ }^{*}$ Larissa Sainz-Núñez, ${ }^{\ddagger}$ José Iván Betanzos-Paz, * Mayra Mejía, ${ }^{*}$ Andrea Estrada, * Jonathan Castillo, * Heidegger Mateos-Toledo*}

*INER Ismael Cosío Villegas; ‘UNISON
RESUMEN. Introducción: Como parte del programa de INMUJERES, el INER recibió presupuesto para apoyo diagnóstico a pacientes con enfermedad pulmonar intersticial difusa (EPID) para ser estudiadas y llegar a un diagnóstico definitivo así como iniciar tratamiento y mejorar su pronóstico a corto plazo. Objetivo: Identificar características de pacientes que ingresaron al programa EPID-INMUJERES durante 2016, así como los diagnósticos que se han realizado con apoyo del programa. Material y métodos: Se recabaron variables demográficas y de pruebas de función respiratoria en pacientes que ingresaron al programa en el período enero-junio 2016. Se registraron los diagnósticos definitivos de acuerdo con la revisión multidisciplinaria realizada por el grupo de enfermedades intersticiales y el laboratorio de neumología traslacional. Se analizaron los resultados con frecuencias, porcentajes, promedios, desviaciones estándar de acuerdo con cada variable. Resultados: Se ingresaron al programa durante el período de estudio 60 mujeres, promedio de edad de $56 \pm$ 16 , las pruebas de función respiratoria corroboraron patrón restrictivo moderado a grave, con incremento de la presión sistólica de la arteria pulmonar. Al realizar las pruebas serológicas se detectó antígeno aviario positivo en $37 \%$, anticuerpos antinucleares positivos en $48 \%$ y de éstos especificidad en 34\%. Se diagnosticaron con historia clínica, tomografía, anticuerpos y en algunos casos lavado bronquioloalveolar/biopsia: 14 casos de neumonitis por hipersensibilidad, 6 neumonías intersticiales no específicas, 3 fibrosis pulmonar idiopática, entre otros. Al momento de este resumen 16 pacientes aún se encuentran en estudio. Conclusiones: Debido a los costos de atención en las EPID, el desarrollo de programas que apoyen a los pacientes para la realización de estudios permite realizar diagnósticos precisos en corto tiempo, aún cuando las pacientes son referidas al Instituto ya con progresión de la enfermedad (restricción moderadagrave) con lo que se inicia tratamiento específico y en un futuro valoraremos el pronóstico de estas pacientes.
Efecto del ozono y PM2.5 de dos temporadas sobre el modelo de asma experimental

\author{
Carlos Iván Falcón-Rodríguez, * \\ Larisa Idania García-Alonso, \\ Brisa Samara Reyes-Nava, ${ }^{*}$ Paulina \\ Mercadillo-Herrera, ${ }^{\star}$ Andrea de \\ Vizcaya-Ruiz, IIrma Rosas-Pérez, \\ Patricia Segura-Medina*
}

*INER Ismael Cosío Villegas; IUNAM; ${ }^{\circledR}$ CINVESTAV

RESUMEN. La contaminación atmosférica es un problema de importancia en la Ciudad de México, ya que diariamente los niveles de ozono $\left(\mathrm{O}_{3}\right)$ y el material particulado $(\mathrm{PM})$ son superados. $\mathrm{El} \mathrm{O}_{3}$ es un gas altamente reactivo, y el PM2.5 es una mezcla de sólidos y líquidos en suspensión, cuya composición difiere en localización y temporadas. Ambos contaminantes son capaces de incrementar las exacerbaciones de asma. Nuestro objetivo fue evaluar la respuesta inmunológica a la inhalación de $\mathrm{O}_{3}$ y PM2.5 de la Ciudad de México en dos temporadas: seca-fría (noviembre-diciembre) y seca-caliente (mayo-junio) utilizando un modelo de asma alérgica, para lo cual se utilizaron 80 cobayos machos (450-500 g). Cuarenta animales en la época seca-caliente y 40 en la seca fría, divididos en 8 grupos. El día 1 se inyectaron con una mezcla de ovalbumina (OVA) como alérgeno más AIOH3 como adyuvante (i.p. e s.c.). Los días 8 y 15 inhalaron OVA (1 mg/mL). Además, inhalaron aire filtrado (AF) o partículas finas (PM2.5) (4 h/día/9 días, $\mathrm{n}=5)$ a través de un sistema concentrador de aerosoles ubicado en CINVESTAV-Zacatenco. Enseguida, mediante un generador de $\mathrm{O}_{3}$ los animales fueron expuestos $(1 \mathrm{~h} /$ día/9 días). El día 21 se realizaron curvas dosisrespuesta de histamina utilizando pletismografía barométrica. 24 horas después se obtuvieron los lavados broncoalveolares para realizar los ensayos de ELISA (Th1/ Th2). El análisis de elementos evidenció diferencias en composición del PM2.5 en relación con la temporada del año. Los animales sensibilizados después de las curvas de histamina demostraron que 
la inhalación de PM2.5 de la temporada seca-fría plus $\mathrm{O}_{3}$ producen un efecto hiperreactor, mientras que la exposición de PM2.5 (seca-caliente) plus $\mathrm{O}_{3}$ indujo un efecto hiporreactor. Nuestro análisis sugiere que la composición del PM2.5 juega un papel importante en la respuesta inmunológica y funcional del asma en nuestro modelo en cobayo. Financiado por SECITI 014/2014.

\section{Quistes pulmonares asociados con síndrome de Down}

\section{Indira Fabiola Cásarez-Sánchez, José Roberto Velázquez-Serratos, Alejandro Alejandre-García}

INER Ismael Cosío Villegas

RESUMEN. Introducción: El síndrome de Down, causado por la trisomía 21, anomalía cromosómica más frecuente. Existe afección multisistémica con problemas respiratorios que los afectan. Los quistes subpleurales aparecen en el 20 a 36\% de estos niños, con mayor frecuencia si hay una cardiopatía congénita asociada. Contribuyen a la formación de estos quistes alteraciones del desarrollo pulmonar: el menor número de alvéolos, el aumento de las dimensiones alveolares y las anomalías del tejido conjuntivo. Mayormente localización periférica (subpleural), pueden aparecer a lo largo de las fisuras pulmonares y troncos broncovasculares. Aparecen en gran número, son pequeños (por lo general de 1-4 mm de diámetro), en comunicación con los espacios aéreos más próximos, diferenciables histológicamente. Cuadro clínico variable, la mayoría asintomáticos y el tratamiento por lo general es conservador. Objetivo: Presentación caso clínico. Material y métodos: Paciente masculino de 4 años con antecedentes perinatales a las 12 SDG, diagnóstico: síndrome de Down, nace 33 SDG por hipoflujo placentario, bajo ventilación mecánica asistida al nacer por 15 días, se egresa al mes de vida, con el diagnóstico de ERGE III, corrección displasia de cadera, fractura fémur derecho, seis eventos de sibilancias, IVRA recurrente, sin cardiopatía congénita. Valorado por

sibilancias persistentes, encontrando quistes subpleurales izquierdos se envía a nuestro instituto bajo diagnóstico de probable malformación adenomatoidea quística. Se realiza TACAR con quistes subpleurales de manera bilateral, valorado por cirugía de tórax, tratamiento quirúrgico con toracotomía, encontrando múltiples quistes menores de 0.5 $\mathrm{cm}$, se realiza resección y pleurodesis. Debido a mejoría se decide su manejo ambulatorio y seguimiento por externo. Resultado y conclusiones: Los quistes supleurales son raramente diagnosticados en pacientes con síndrome de Down, es importante que se identifique ya que pueden aumentar el riesgo de neumotórax y otras lesiones del parénquima durante el posoperatorio o durante la ventilación mecánica. Reconocer la asociación con esta cromosopatía para no confundir con otras entidades.

\section{La secreción de integrinas y alteraciones de adhesiones focales en un modelo de asma}

\section{Mayra Dinorah Álvarez-Santos, * Verónica Carbajal, ${ }^{*}$ Olivia Téllez- Jiménez, * Erasmo Martínez-Cordero, ${ }^{*}$ Víctor Ruíz, * Rogelio Hernández- Pando, $\neq$ Ricardo Lascurain*}

*INER Ismael Cosío Villegas; ₹INCMN

RESUMEN. Los dominios extracelulares de algunas proteínas de membrana pueden ser cortados de la célula. Un fenómeno similar ocurre con $\beta 1$ integrinas $(\alpha 1 \beta 1$ y $\alpha 2 \beta 1$ ) en cobayo. El supuesto papel de las alteraciones de la subunidad $\beta 1$ integrina derivado de los cortes en el músculo liso de las vías aéreas en un modelo de asma alérgica fue evaluado. Los cobayos fueron sensibilizados y retados con antígeno. Los retos antigénicos indujeron broncoobstrucción e hiperreactividad de las vías aéreas en el tercer reto antigénico. Los estudios con inmunohistoquímica y con microscopia inmunoelectrónica mostraron que los dominios citosólico y extracelular de la subunidad $\beta 1$ integrina comparten la misma distribución en estructuras de las vías aéreas en ambos grupos. Varios polipéptidos con pesos moleculares similares fueron detectados con anticuerpos específicos para los dominios de la subunidad $\beta 1$ integrina, citosólico y extracelular en miocitos aislados de las vías aéreas y el tejido conectivo que rodea la banda de músculo liso. Estudios en citometría de flujo y Western blot mostraron que la expresión del dominio citosólico y extracelular de la subunidad $\beta 1$ de integrina en músculo liso de las vías aéreas fue similar entre los grupos. Se observó un incremento en el mRNA de ITGB1 en músculo liso de las vías aéreas en el grupo con modelo de asma. RACEPCR de ITGB1 en músculo liso de las vías aéreas no mostró variantes por empalme alternativo. Los niveles de expresión de la cinasa ligada a integrina (ILK) y paxilina disminuyeron en el modelo de asma pero no talina. Los niveles de fosforilación de la fosfatasa de miosina (MYPT1) en Thr696 incrementaron en el modelo de asma. Nuestro trabajo sugiere que la subunidad $\beta 1$ integrina es secretada en la pared de las vías aéreas de cobayos. Esta secreción no es alterada en el modelo de asma, sin embargo, el dominio citosólico de $\beta 1$ integrina ensambla proteínas en adhesiones focales de la célula, en las cuales, ILK y paxilina están involucradas y alteradas en el modelo de asma.

\section{Estudio de vida real del uso de pirfenidona en neumonitis por hipersensibilidad crónica}

Edith Aimé Alarcón-Dionet, José Iván Betanzos-Paz, Michelle Alejandra Burciaga-Verduzco, Karen Pamela Martínez-Espinosa, Ivette BuendíaRoldán

INER Ismael Cosío Villegas

RESUMEN. Introducción: La pirfenidona es un medicamento antifibrosante que ha sido aceptado para el tratamiento de fibrosis pulmonar idiopática (FPI). La neumonitis por hipersensibilidad crónica (NHc) comparte características tomográficas y de morfología similares a la FPI, incluso se ha reportado un patrón usual similar al de FPI, por lo que es de interés 
determinar si agregar pirfenidona al tratamiento estándar de la NHc mejora la función respiratoria. Objetivo: Evaluar las pruebas de función pulmonar a 15 meses de pacientes con diagnóstico de NHC que reciben tratamiento estándar más pirfenidona. Metodología: Analizamos la cohorte de NHc que ha recibido prednisona, azatioprina y pirfenidona al momento de ingreso al estudio y a 15 meses de seguimiento. Identificamos las causas de retiro del protocolo en este período de tiempo. Se evaluaron las variables con medidas centrales y dispersión, así como la delta en las pruebas de función respiratoria para cada paciente. Resultados: El grupo que recibió de manera inicial tratamiento estándar más pirfenidona fue de 20 pacientes, de los cuales han completado 15 meses de seguimiento 16 pacientes. Se presentan las características demográficas y pruebas de función respiratoria basales. Las causas de retiro en los cuatro pacientes fueron: efectos gastrointestinales y fotosensibilidad. Conclusión: El agregar al tratamiento estándar pirfenidona, ha mostrado a 15 meses en pacientes con NHc estabilidad en la mitad de los casos; sin embargo, una limitación importante de este estudio es la gravedad que presentaban los pacientes de manera inicial, por lo que se requieren estudios posteriores para determinar el efecto real de la pirfenidona.

\section{Alteración en la función respiratoria secundaria a neumonitis química por bario}

\section{María del Carmen Castillo-Villatoro, Job Santamaría-Aldaco, Roberto Velásquez, Margarita Salcedo- Chávez, Teresa Leal-Arriaga}

INER Ismael Cosío Villegas

RESUMEN. Paciente masculino de 9 años. Prenatales: producto de la gesta 2 (G4P2C2A2), se realiza citología cervical se refiere normal, refiere control prenatal adecuado desde el primer trimestre, ingesta de multivitamínicos, hierro, ácido fólico, con vacunación de Td durante embarazo, ultrasonidos durante embarazo + reportados como normales, con infecciones tercer trimestre, niega amenazas de aborto, amenaza parto pretérmino desde las 36 años. Perinatales: obtenido por vía cesárea por alteraciones en la placenta y RCIU, hospital IMSS, se obtiene de 38 SDG, llora y respira al nacimiento, Apgar 9/9 y peso al nacer $2.31 \mathrm{~kg}$. Se egresa binomio sano después 48 horas, caída del cordón umbilical, evacúa en las primeras 24 horas de vida. Posnatales: seno materno tres meses, fórmula hasta los 48 meses, ablactación a los seis meses con papillas frutas verduras (alimentos alergénicos antes del año: huevo, chocolate, mariscos, preguntados y negados). Antecedentes personales patológicos: Hospitalizaciones: a los dos años por neumonitis química por broncoaspiración, requiere terapia intensiva, ventilación mecánica por 48 horas, 4 días con $\mathrm{O}_{2}$, se egresa sin oxígeno, se realiza broncoscopia, en período de dos semanas se traslada a IMSS Siglo XXI, se realiza otra broncoscopia en junio 2008. Niega Qx, traumatismos, transfusionales, sinusitis, neumonía, otitis. MDI: tx alvezco 200 cada 24 horas. Última ocasión de dificultad respiratoria y sibilancias: hace dos meses. Sibilancias: desde el año de vida con episodios de sibilancias. Padecimiento actual: Masculino de 10 años con antecedente de neumonitis por broncoaspiración de medio de contraste (bario a los dos años), requiriendo manejo por dos días con ventilación mecánica en terapia intensiva en Veracruz, con broncoscopia en dos ocasiones para aspirar medio de contraste, traslado a la Ciudad de México para seguimiento y control en INER. Acude a hospitalización para seguimiento y realizar estudios de función pulmonar, ya que refiere disnea de medianos a grandes esfuerzos, refiere al caminar una cuadra, al subir escaleras y al jugar antes de media hora de actividad. Acude paciente masculino de 9 años con antecedente de broncoaspiración de bario a los 2 años, requiere terapia intensiva y ventilación mecánica, se realiza broncoscopia en dos ocasiones en período de 2-3 semanas para aspiración de medio de contraste, se conoce con diagnóstico de asma y se ha valorado por consulta de sueño, dado de alta, alergología, egresado y cardiología, tratamiento con alvezco 1 disparo 200 cada 24 horas. Se hospitaliza ya que refiere disnea de medianos esfuerzos además de desnutrición y talla baja, por lo que requiere valoración. Además, refiere síntomas de reflujo por lo que se debe abordar por dicha sintomatología nuevamente ya que se encuentra sin tratamiento. La aspiración accidental de medio de contraste ocurre hasta en $8 \%$ de pacientes con reflujo en valoración, siempre es una situación grave y que muchas veces tiene desenlace fatal, produciendo alteraciones en la difusión y VQ, al dañar los espacios alveolares, el tratamiento es inicialmente soporte vital y broncoscopia para aspiración del medio, sin embargo, en todos los casos es imposible aspirar todo el medio, antibiótico para los que presentan datos de neumonía, sospecha de aspiración de contenido gástrico o que en 48 horas no presente mejoría. El paciente requiere nuevo estudio de imagen, además de pruebas funcionales respiratorias, cuenta con oscilometría con afección de vía aérea pequeña con respuesta a broncodilatador, espirometría con obstrucción fija y requiere caminata para valorar disnea, DLCO, motivo por el cual se hospitaliza.

\section{Síndrome de Jacobsen}

\section{Yunuen Rocío Huerta-Villalobos, Beatriz Andrea Muñoz-Gómez, Alejandro Cano-Verdugo, Yesid Brian Oliden-Saavedra, Gandhi Fernando Pavón-Romero, María de la Luz Hortencia García-Cruz, Fernando Ramírez-Jiménez}

INER Ismael Cosío Villegas

RESUMEN. Introducción: Descrito en 1973, el síndrome de Jacobsen (SJ) es una deleción parcial del cromosoma 11q, generalmente por mutaciones de novo, se manifiesta con múltiples anomalías congénitas como retraso mental, trigonocefalea, dismorfia facial, anormalidades cardíacas, gastrointestinales, musculoesqueléticas y hematológicas. Presentación de caso: Paciente masculino de 16 años valorado por probable inmunodeficiencia primaria. Antecedente de dos neumonías, hipoacusia bilateral, retraso psicomotor, persistencia de conducto arterioso, estenosis congénita de aorta, frenuloplastía y alargamiento de tendón calcáneo, evento 
vascular cerebral isquémico frontal con secuela de crisis convulsivas y parálisis diafragmática derecha intervenida con plicatura diafragmática y colocación de sello pleural. A su evaluación en consulta externa presentaba linfocitos y neutrófilos de 1,500, trombocitopenia de 82,000, IgA $<7 \mathrm{mg} / \mathrm{dL}$ (2 determinaciones), resto de parámetros dentro de límites normales. Discusión: El SJ presenta una incidencia < $1 / 100,000$ nacimientos, $65 \%$ de los afectados tienen anormalidades en SNC y $>90 \%$ presenta retraso psicomotor, lo que afecta funciones básicas como deglución, manejo de secreciones lo que se puede complicar con neumonías de repetición por el riesgo de broncoaspiración. La gravedad del espectro clínico tiene relación directa con el tamaño de la deleción. Conclusión: La deficiencia selectiva de $\operatorname{IgA}$ generalmente presenta un curso benigno, sin embargo, se debería de descartar esta enfermedad como un subgrupo de deficiencia selectiva de $\operatorname{Ig}$ A dado que las complicaciones que suelen llegar a tener son graves. La esperanza de vida para los pacientes que sobreviven al período neonatal y la infancia permanece desconocida hasta la fecha como en el caso de nuestro paciente.

\section{Uso de anestésicos locales en paciente con alergia a lidocaína. Reporte de un caso}

\section{Alejandro Cano-Verdugo, Yunuen Rocío Huerta-Villalobos, Beatriz Andrea Muñoz-Gómez, Yesid Brian Oliden-Saavedra, Gandhi Fernando Pavón-Romero, María de la Luz García-Cruz, Fernando Ramírez-Jiménez}

INER Ismael Cosío Villegas

RESUMEN. Introducción: Los anestésicos locales (AL) bloquean canales de sodio inhibiendo la despolarización celular, evitando de manera reversible la nocicepción, por lo que son empleados en diversos procedimientos; empíricamente se tiende a suspender su uso cuando existen reacciones alérgicas a alguno de ellos, aunque su incidencia sea $<1 \%$. Caso clínico: Paciente masculino de 53 años con EREA y poso- perado de uretrotomía, con dilataciones uretrales repetidas desde hace seis años para evitar la reestenosis. Hace dos meses presentó súbitamente opresión torácica, sibilancias e hipotensión posterior a bloqueo del nervio dorsal del pene con lidocaína. Ulteriormente se le han realizado dilataciones uretrales consecutivas sin anestésico sin complicaciones. Por requerimiento de intervención dental se envía a alergología. En su evaluación se reportó asintomático, exploración física sin datos relevantes. Asma clínicamente controlada. Biometría hemática, química sanguínea y niveles de inmunoglobulinas normales, pruebas cutáneas a aeroalérgenos negativas. Espirometría normal sin respuesta significativa a broncodilatador. Prueba intradérmica con lidocaína positiva. Se realizó reto con bupivacaína siendo negativo. Discusión: Los anestésicos locales están formados químicamente por una amina terciaria unida a un grupo lipofílico mediante un enlace amida o éster. En alergia a anestésicos tipo éster debe evitarse el uso de otros miembros de esta familia, por reactividad cruzada con el ácido paraaminobenzoico; en contraste, en alergia a aminoamidas es seguro emplear agentes del mismo grupo, debido a su baja reactividad cruzada; no obstante, el estándar de oro para diagnosticar la alergia a AL es la prueba de reto. Las formulaciones pueden contener estabilizadores, antioxidantes e inhibidores de crecimiento microbiano (metilparabenos, sulfitos, látex) capaces de generar reacciones alérgicas. Conclusión: En el presente caso se recomendó el uso de otro AL tipo amida (bupivacaína), previa medicación con antihistamínico-H1 y prednisona.

\section{Proteinosis alveolar y tratamiento de lavado broncoalveolar total con cánula de doble lumen}

María del Carmen Castillo-Villatoro, Luisa Martínez-Valdeavellano, Pablo Cortés-Borrego, Rosangela del Razo, Alejandro Varela-Luna

INER Ismael Cosío Villegas

RESUMEN. Introducción: La proteinosis alveolar pulmonar es un trastorno poco común caracterizado por la acumulación de un material lipoproteico dentro de los alvéolos. Se reconocen cuatro formas en los niños: congénita, adquirida, secundaria e idiopática. La forma congénita es generalmente causada por errores innatos del metabolismo del surfactante o por un defecto en el transporte de membrana plasmática de aminoácidos, la clínica presentación puede variar de insuficiencia respiratoria grave en el período neonatal a síntomas más insidiosos de enfermedad crónica pulmonar intersticial en niños mayores. En los niños mayores el diagnóstico generalmente se planteó durante el transcurso de una evaluación para síntomas y signos inespecíficos de la enfermedad pulmonar. El diagnóstico es sugerido por los hallazgos radiológicos y confirmado por broncoscopia y/o biopsia pulmonar. Estos niños también deben hacerse la prueba de antiGM-CSF anticuerpos para evaluar proteinosis adquirida, aunque esta forma es rara en niños. Presentación de caso: Paciente femenino de 12 años quien consulta por disnea, dificultad respiratoria de 24 horas de evolución, el paciente se encontraba haciendo ejercicios en educación física, se acompaña de tos productiva no cianotizante no emetizante, con predominio matutino, cefalea, el paciente refiere que al caminar una cuadra hay cansancio. Actualmente con tx levocetirizina, fluticasona 27.5 intranasal, seretide de 25/250 dos disparos cada 24 horas. A la evaluación física con hipoxemia, vibraciones vocales disminuidas, datos de no dificultad respiratoria, ruidos respiratorios disminuidos, con presencia de estertores crepitantes fino subescapulares bilaterales, no sibilancia. Exámenes de laboratorio de ingreso: leucocitos $7.900 / \mathrm{mm}^{3}$, neutrófilos $90.2 \%$, linfocitos $7.9 \%$, hemoglobina $14.9 \mathrm{~g} / \mathrm{dL}$, hematócrito $45.5 \%$, plaquetas 203.000/ $\mathrm{mm}^{3}$, desidrogenasa láctica $228 \mathrm{UI} / \mathrm{L}$, TGO 30, TGP 15, perfil inmunológico IGE 444, proteína $\mathrm{C}$ reactiva 0.02 , factor reumatoide menor 20, antiestreptolisina 91 , hemocultivo y baciloscopias negativo, PPD 0 mm CD45, CD4, CD8, cociente CD4/ CD8 normal, CD3 disminuida, gasometría venosa con equilibrio ácido base, antígeno aviario negativo, pruebas de función respiratoria ingreso espirometría PRE $\mathrm{FEV}_{1} / \mathrm{FVC}$ 76.71\% $\mathrm{FEV}_{1}$ 1.26 ML FVC 
1.64 ML espirometría con obstrucción moderadamente grave, espirometría POS 86.7\% FEV 1.32 ML FVC 1.52 ML espirometría sugestiva de restricción, DLCO disminución moderada corregida por altitud $42 \%$, pletismografía con restricción pulmonar leve y atrapamiento aéreo grave, electrocardiograma ritmo sinusal trazo normal, Rx de tórax ángulo costofrénico y costodiafragmático borrados, mal definidos, se observan múltiples imágenes radiopacas difusas de bordes mal definidos e imágenes sugestivas de bronquiectasias en forma de riel hemitórax derecho, imágenes radiopacas paracardíaca derecha e izquierda que hace signo de silueta con presencia de broncograma aéreo, TACAR engrosamiento de tabique interlobulillar dando patrón en crazy paving, se realiza broncoscopia donde se evidencia cambios inflamatorios agudos en la totalidad de mucosa traqueobronquial, moderadas secreciones mucohialinas en todo el árbol bronquial, proteinosis alveolar (líquido blanquecino) estudios de LBA: genexpert MTB, cultivo, Gram, grocott, negativo, frotis LBA detritus celulares, abundantes cúmulos de material proteináceo, macrófagos, escasos eosinófilos, células bronquiales con cambios inflamatorios y células de metaplasia epidermoide. Estudio anatopatológico: alteraciones inflamatorias con escasa evidencia hemorragia antigua. Reporte citológico: Material producto de lavado bronquioloalveolar color blanquecino, de aspecto grumoso, material granular eosinófilo, con detritus celulares, bacterias y macrófagos. Posteriormente se realiza lavado broncoalveolar dando diagnóstico de proteinosis alveolar idiopática. El Servicio de Reumatología sugiere realizar estudios anticuerpos antifactor estimulante de colonias de granulocitos monocitos, antinucleares, antiPR3, MPO y ANCA valorando el inicio de Tx factor estimulante de colonia-MG, se egresa paciente estable sin uso de oxígeno con espirometría con sugestiva de restricción.

\section{Nueva metodología para fraccionar proteínas membranales compatible con electroforesis en gel de dos dimensiones}

\section{Luis Ángel Pérez-Moreno, Héctor Guillermo Cordero-García, Pedro Vargas-Leonor, Fernando Hernández-Sánchez, Carlos Cabello-Gutiérrez}

INER Ismael Cosío Villegas

RESUMEN. Introducción: El proteoma es el conjunto global de proteínas asociado con una condición biológica. El mayor reto del análisis proteómico consiste en discernir la presencia, abundancia y estado de modificación postraduccional de moléculas individuales dentro de una mezcla compleja de proteínas y la electroforesis bidimensional (2DE) que separa a las proteínas por punto isoeléctrico y peso molecular, es la única herramienta capaz de separar a las miles de proteínas que expresa una célula; sin embargo, al separar fracciones subcelulares como la membrana plasmática, la complejidad disminuye y la resolución aumenta. Algunos métodos de separación de proteínas membranales se basan en hidrofobicidad y no en la ubicación, además de usar detergentes iónicos incompatibles con 2DE, lo cual es una limitante para la interpretación. Objetivo: Generar una estrategia para separar proteínas membranales, citoplasmáticas y nucleares basados en su localización y compatible con 2DE. Métodos: Las de células MDCK adherentes se despegaron con EDTA y sin estrés mecánico, se cosecharon por centrifugación suave. Se lavaron con PBS y se lisaron por congelamiento. La fracción citoplasmática se obtuvo por choque osmótico con solución hipotónica. Para recuperar el contenido nuclear se utilizó solución hipertónica y centrifugación a alta velocidad. Las membranas se resuspendieron en sacarosa de alta densidad y se sometieron a ultracentrifugación. Las proteínas precipitadas se disolvieron con detergentes no iónicos y agentes caotrópicos. El contenido total se analizó por electroforesis 2DE y con azul de Coomasie o tinción de plata. La presencia de proteínas que pertenecen a cada fracción se evaluó por Western blot. Resultados: Se observó un enriquecimiento de las proteínas de cada fracción y un efecto empobrecido de contaminantes asociados en comparación con una separación basa- da en hidrofobicidad. Conclusiones: Este trabajo presenta una metodología sencilla de extracción de proteínas membranales, citoplasmáticas y nucleares de la misma muestra y compatible con 2DE.

\section{Traqueobroncopatía osteocondroplástica. Reporte de un caso}

\author{
Olivia Sánchez-Cabral, \\ Dina Martínez-Mendoza, \\ Miguelina Altagracia Jáquez-Carras, \\ Iván Rodolfo García-Izquierdo, \\ María Eugenia Vázquez-Martínez, \\ Berenice López-González, \\ María Angelina Contreras-Cortés
}

INER Ismael Cosío Villegas

RESUMEN. Introducción: La traqueobroncopatía osteocondroplástica es una rara enfermedad. Se encuentra incidentalmente en 1:2,000 broncoscopias. El origen de esta lesión es controversial, se ha asociado con tuberculosis, papilomatosis, policondritis, granulomatosis de Wegener, amiloidosis e infecciones por Klebsiella ozenae. Histológicamente se caracteriza por metaplasia escamosa (40\%), cartílago en la submucosa (38\%), hueso (58\%) y calcificaciones (20\%). Objetivo: Describir el caso de una enfermedad poco frecuente como hallazgo broncoscópico y su traducción histopatológica. Presentación del caso: Hombre de 48 años de edad, residente del Estado de México, afilador, con antecedente de etilismo intenso durante 16 años. En febrero de 2016 presentó tos con expectoración de color amarillenta, fiebre de $38{ }^{\circ} \mathrm{C}$, dolor pleurítico en hemitórax derecho. En radiografías muestra consolidación en lóbulo inferior derecho, tratado con ceftriaxona/claritromicina por 10 días, sin mejoría. Fue referido al INER donde se realizó TAC contrastada que reveló derrame pleural derecho, el análisis fisicoquímico concluyó empiema, ameritando manejo con sonda endopleural. En su evolución presentó choque séptico secundario a infección pulmonar por Stenotrophomona maltophilia, tratada con meropenem y tigeciclina. Requirió siete días de soporte con ventilación mecánica, a las 48 horas posextubación presentó atelectasia derecha completa, por lo que se 
realizó broncoscopia diagnóstica. Durante la exploración de la vía aérea se observan múltiples lesiones nodulares de 1-6 mm en todo el trayecto de la tráquea y bronquios principales, de consistencia pétrea y resistente a criosonda. En vista de los hallazgos y diagnóstico no concluyente se decidió una segunda exploración con toma de biopsias con pinzas rígidas. El reporte histopatológico concluyó traqueobroncopatía osteocondroplástica. Al final el paciente mejoró significativamente, egresando tras 21 días de tratamiento antibiótico, al presente sigue en seguimiento por consulta externa. Conclusiones: Debido a que existe una amplia gama de enfermedades con afección traqueobronquial con manifestaciones clínicas similares, es importante considerar diagnósticos diferenciales, sobre todo mediante el estudio histopatológico puesto que éste impacta en el pronóstico y tratamiento.

\section{Utilidad del ultrasonido endobronquial en pacientes infectados por el virus de inmunodeficiencia humana y linfadenopatía mediastinal}

\section{Olivia Sánchez-Cabral, Dina Martínez-Mendoza, Miguelina Altagracia Jáquez-Carrasco, Berenice López-González, Iván Rodolfo García-Izquierdo}

INER Ismael Cosío Villegas

RESUMEN. Antecedentes: Existen pocos estudios publicados de la utilidad del ultrasonido endobronquial (EBUS) en pacientes infectados por el virus de la inmunodeficiencia humana (VIH). El espectro clínico de las enfermedades probables en esta población es variada y difiere de los pacientes no infectados por VIH. Objetivo: Medir la utilidad de la punción transbronquial con aguja guiada por EBUS (EBUS-TBNA) en pacientes infectados por VIH con presencia de linfadenopatía mediastinal. Material y métodos: Estudio observacional, transversal, retrospectivo, descriptivo. Pacientes con infección por VIH y linfadenopatía mediastinal en quienes se realizó EBUS-
TBNA entre septiembre 2014 y abril 2016. Se consideró como estándar de oro positivo el diagnóstico final del paciente independientemente de la muestra que lo hubiere dado y el negativo la ausencia de diagnóstico. Se midió el rendimiento diagnóstico, la sensibilidad (S), especificidad (E), valor predictivo positivo (VPP), valor predictivo negativo (VPN) y la precisión diagnóstica del lavado broncoalveolar (LBA), biopsias transbronquiales (BTB) y de EBUS-TBNA. Resultados: Se realizaron un total de 43 procedimientos, $79.1 \%$ (34/43) correspondió al sexo masculino, la mediana de edad fue 35 años (R: 22-66). El rendimiento diagnóstico global considerando todos los tipos de muestras fue de $90.7 \%$ (39/43), el rendimiento del LBA fue $50 \%$ (21), las BTB de $61.9 \%$ (26) y el EBUS-TBNA $60.5 \%$ (26). El rendimiento conjunto LBA con BTB fue $69.8 \%$ (30), LBA con EBUS-TBNA 86\% (37); y el rendimiento conjunto BTB con EBUS-TBNA $88.4 \%$ (38). La precisión diagnóstica más alta fue $97.7 \%$ dada por la combinación BTB y EBUS-TBNA. Conclusiones: En pacientes con infección por VIH y linfadenopatía mediastinal EBUS-TBNA tiene un alto rendimiento diagnóstico principalmente cuando se combina con BTB. Los diagnósticos benignos infecciosos fueron los más frecuentes, siendo la tuberculosis el más prevalente con una precisión diagnóstica más alta por EBUS-TBNA que por LBA. En patología maligna tanto el EBUS-TBNA como las BTB fueron útiles. EBUS-TBNA es una herramienta diagnóstica mínimamente invasiva que debe ser considerada en este tipo de pacientes.

\section{Complicaciones en pacientes sometidos a traqueostomía percutánea durante el período 2014-2015 en el INER}

Olivia Sánchez-Cabral,

Dina Martínez-Mendoza, Miguelina Altagracia Jáquez-Carrasco, Iván Rodolfo García-Izquierdo, Mauro Enseñat-Faisal, Berenice López-González

INER Ismael Cosío Villegas
RESUMEN. Introducción: En las unidades de cuidados intensivos un importante número de pacientes requiere traqueostomía percutánea (TP) por ventilación mecánica prolongada. La TP es un procedimiento mínimamente invasivo en el que el abordaje traqueal guiado por broncoscopia y mediante técnica de Seldinger se está imponiendo como técnica de primera elección en Europa, Estados Unidos y México. Objetivo general: Identificar complicaciones en pacientes sometidos a traqueostomía percutánea y cuantificar las decanulaciones tras prueba de deglución. Material y métodos: Estudio de investigación clínica, observacional, descriptivo, retrospectivo, transversal. Población de estudio: Pacientes mayores a 18 años hospitalizados en el INER a quienes se les realizó traqueostomía percutánea entre enero 2014-diciembre 2015. Se revisaron expedientes en el archivo clínico. Resultados: Se realizaron 165 traqueostomías percutáneas, el sexo masculino representó el $67.3 \%$ (111), la media de edad fue de 51.5 años (DE \pm 16.7$)$, la mediana en días de estancia intrahospitalaria fue de 42.0 (11-404). Los diagnósticos más frecuentes fueron: neumonía en el $89.7 \%$ (148), choque séptico en $73.9 \%$ (122). Los agentes etiológicos más frecuentemente identificados fueron influenza AH1N1 23\% (38), Pseudomonas aeruginosa 37\% (61), Stenotrophomonas maltophilia $13.3 \%$ (22), Acinetobacter baumannii 7.9\% (23). Las comorbilidades más frecuentes fueron: cor pulmonale en $15.2 \%$ (25), EPOC en $12.7 \%$ (21) y VIH en $18.8 \%$ (31). La incidencia de complicaciones por TP fue de 5.5\% (9), 6 hipoxemia, 1 neumotórax, 1 insuficiencia glótica, 1 estenosis traqueal. Mientras que la tasa de mortalidad fue de $37.0 \%$ (61). Al 54.5\% (90) de los pacientes se les realizó pruebas de deglución, se decanuló exitosamente al 82.2\% (74). Las principales diferencias entre los pacientes decanulados y los que no se debieron a trastornos de deglución y/o ausencia de reflejos de tos, diferencias estadísticamente significativas $(\mathrm{p}<0.005)$. Conclusión: Nuestro estudio demuestra que la TP es un procedimiento seguro con una baja tasa de complicaciones en pacientes críticamente enfermos. La prueba de deglución predice la decanulación exitosa. 


\section{Validación de ecuaciones de predicción capacidad inspiratoria en población que reside 2,240 metros de altura}

\section{Ireri Isadora Thirión-Romero, Silvia Cid-Juárez}

INER Ismael Cosío Villegas

RESUMEN. Introducción: La medición de los volúmenes pulmonares otorga información útil acerca de las distintas enfermedades pulmonares. La CI es un parámetro importante para determinar la presencia de hiperinflación dinámica en EPOC y otras enfermedades obstructivas, disnea y mortalidad; así como la tolerancia al ejercicio y la efectividad a los broncodilatadores. Hipótesis: Los valores de la CI obtenidos en población sana que habita en altitud moderada no ajustan a las ecuaciones publicadas previamente. Objetivos: Comparar los valores de CI en población sana que habita en altitud moderada con las diferentes ecuaciones. Material y métodos: Fecha de estudio: mayo de 2014 a agosto de 2015 en el Laboratorio de Función Pulmonar del INER, en sujetos sanos que habitan en altitud moderada, mayores de 9 años de edad. Se realizó espirometría lenta de acuerdo con los estándares de ATS/ERS. Análisis estadístico: se realizo modelos de regresión lineal y los resultados fueron comparados con los valores esperados por ecuaciones previamente publicadas. Resultados: Se estudiaron 441 sujetos sanos, $45.12 \%$ varones, la mediana de edad fue de 32 años. La CI fue mayor estadísticamente en hombres $(3.66 \pm 0.75 \mathrm{~L})$. En la población estudiada durante la etapa de crecimiento hasta los 20 años, existe un incremento acelerado de la CI y después se observa una caída más pronunciada en mujeres. Se graficaron las mediciones de CI obtenidas y se compararon con las estimaciones de otras ecuaciones, observando que ninguna ecuación ajustó a la población estudiada. Conclusiones: Los valores evaluados para CI en nuestra población, mostraron valores por encima de los esperados para la talla, el género y la edad de sujetos europeos y latinoamericanos. No recomendamos utilizar ecuaciones publicadas para predecir la CI en población que resida altitud moderada. Por lo que es importante utilizar valores locales para esta población.

\section{Utilidad de las criobiopsias pulmonares y endobronquiales en enfermedad pulmonar no intersticial}

Olivia Sánchez-Cabral, Dina

Martínez-Mendoza, Berenice LópezGonzález, Patricia Carolina PereaTalamentes, Iván Rodolfo GarcíaIzquierdo, Miguelina Altagracia Jáquez-Carrasco

INER Ismael Cosío Villegas

RESUMEN. Introducción: Aunque la biopsia pulmonar quirúrgica se considera el estándar de oro para la toma de muestras pulmonares, las criobiopsias han demostrado menor morbimortalidad y costos, ya que pueden realizarse de forma ambulatoria, su uso se ha estandarizado en enfermedades intersticiales con rendimiento de hasta $85 \%$. Hipótesis: El uso de criosondas para biopsias pulmonares es un método seguro con alto rendimiento diagnóstico. Objetivo general: Medir el rendimiento diagnóstico de las criobiopsias pulmonares guiadas por fluoroscopia y endobronquiales en la Unidad de Neumología Intervencionista del INER. Material y métodos: Se incluyeron pacientes $>18$ años a quienes se les realizaron criobiopsias en el período de mayo de 2015 a abril de 2016. Se revisaron las bases de datos de la unidad, los expedientes clínicos en el Archivo Clínico del Instituto y las tomografías en el sistema Magic Web. Se analizó el rendimiento diagnóstico utilizando $\chi^{2}$ y prueba t de Student, se consideró significativa una $\mathrm{p}<0.05$. Software IBM SPSS Statistics 21. Resultados: Se realizaron un total de 121 criobiopsias. El $62.8 \%$ (76) correspondieron a pacientes de sexo masculino, la media de edad fue de 51.9 (DE \pm 18.2) años. El 25.6\% (31) de los pacientes tenían infección por virus de inmunodeficiencia humana (VIH).
También se hizo LBA en el 90.9\% (110). El rendimiento diagnóstico global fue de $90.9 \%$ (110/121), para criobiopsias fue de $75.2 \%$ (91/121). El $41.3 \%$ (50/121) tuvo diagnóstico de malignidad, 23\% (27/121) correspondieron a adenocarcinoma; $39.7 \%$ (48/121) tuvieron diagnósticos benignos, los principales agentes fueron micobacterias y $P$. jirovecii. El 9.1\% (11) de nuestra población presentó alguna complicación, no se registraron defunciones. Conclusión: Las criobiopsias demostraron un alto rendimiento diagnóstico en enfermedad pulmonar no intersticial, sobre todo en pacientes con sospecha clínica de neoplasias. Es posible la identificación de agentes microbiológicos en población VIH y no VIH. Demostró ser un procedimiento seguro con una tasa baja de complicaciones.

\section{Efectividad de la biopsia pleural quirúrgica en pacientes con derrame de tipo exudativo. Estudio prospectivo}

\section{Víctor Hugo Zotés-Valdivia, Marco Antonio Iñiguez-García}

INER Ismael Cosío Villegas

RESUMEN. Objetivo: Determinar la eficacia de la biopsia pleural quirúrgica en el diagnóstico de los pacientes con derrame de tipo exudativo. Metodología: Se realizó un estudio prospectivo desde diciembre de 2013 a noviembre de 2014. Se tomaron en cuenta datos demográficos, efectividad diagnóstica, resultados histopatológicos, morbilidad y mortalidad. El análisis estadístico mediante SPSS versión 22. Resultados: Se realizaron en nuestro instituto 77 biopsias pleurales, $45.5 \%$ (n $=35$ ) de sexo masculino y $54.5 \%$ ( $\mathrm{n}=$ 42) femenino. Edad promedio de 60. El abordaje por toracoscopia representó el $84.4 \%(n=65)$ y en el $64.6 \%$ de éstas se utilizó un solo puerto. El número de muestras en más de la mitad de los casos fue de $2(50.6 \%)$. La pleurodesis se realizó en el $36.4 \%(n=28)$, con una efectividad de $78.6 \%$. La efectividad diagnóstica fue de $87 \%$ y los resultados histopatológicos se distribuyeron de la siguiente manera: 
$72.7 \%(\mathrm{n}=56)$ neoplásicos; $11.7 \%(\mathrm{n}=9)$ infecciosos, $2.6 \%(n=2)$ de origen reumatológico y $13 \%(\mathrm{n}=10)$ de etiología no determinado. Del total de los neoplásicos, el $60.7 \%$ fueron metastásicos y $39.3 \%$ tumores primarios pleurales, de los cuales el mesotelioma fue el más representativo, $86.4 \%$ de los tumores primarios de pleura y $24.7 \%$ del total de la serie. De los nueve resultados infecciosos $44.4 \%(n=4)$ fueron por tuberculosis. La morbilidad transoperatoria y posoperatoria fueron de 7.8 y $10.4 \%$, respectivamente. La mortalidad de $2.6 \%$. Conclusiones: La biopsia quirúrgica en nuestro instituto ha demostrado ser un procedimiento diagnóstico altamente efectivo comparado con otras técnicas cerradas de otras series importantes; aunque la rentabilidad diagnóstica está un poco por debajo del promedio comparándola con otras series similares en las que alcanza el $90 \%$ o más.

\section{Reporte de un caso. Swyer-James-MacLeod}

\section{Jorge Alemán-Zapata, Isaac Rodríguez-Saldaña, Brenda Avilés-Ramírez, Roberto Velázquez-Serratos}

INER Ismael Cosío Villegas

RESUMEN. Introducción: El síndrome Swyer-James-MacLeod presenta una prevalencia de $0.01 \%$. Se caracteriza clásicamente por un pulmón hiperluciente unilateral. Las manifestaciones clínicas varían desde formas asintomáticas hasta infecciones respiratorias de repetición con tos productiva, disnea y hemoptisis ocasional. Objetivo: Describir el abordaje diagnóstico de paciente con Swyer-JamesMacLeod. Desarrollo: Paciente masculino de 7 años de edad, originario de la Ciudad de México. A los siete meses de edad presentó hospitalización en hospital de seguro con el diagnóstico de neumonía. Posterior presenta múltiples ingresos por eventos de sibilancias en más de siete ocasiones, se lleva a biopsia pulmonar. Reporte histopatológico: Bronquioalveolitis crónica grado leve PB secundaria a proceso viral. Ingresando a INER por las quejas de respiración episódicas pro-

fundas y prolongadas, con sensación de disnea ocasional, sin ruidos pulmonares acompañantes y sin dificultad respiratoria. Se realiza abordaje en donde TAC: presencia de pulmón derecho hiperclaro con patrón de mosaico, disminución en el calibre de la pulmonar en la fase contrastada. Gammagrama VQ: concluyendo asimetría por severa disminución de la perfusión y ventilación en pulmón derecho. Broncoscopia con cambios inflamatorios y mucosa pálida en árbol bronquial derecho. Conclusiones: Se inicia abordaje por PB síndrome James Mcleod PB secundario a procesos infecciosos referido en nota de egreso de hospital de seguro. El Swyer-James-MacLeod es resultado de una disminución de volumen pulmonar secundario a la obliteración bronquiolar que aparece adquirida tras una bronquiolitis y/o neumonía en la infancia. En la mayoría de estos niños, si no hay una enfermedad asociada, el pronóstico es excelente, pudiendo disminuir los síntomas con el paso del tiempo. Muchos de los niños diagnosticados o no, continuarán su vida sin ningún tipo de problema.

\section{Pectus excavatum como causa de síncope: corrección quirúrgica y su evolución posoperatoria}

\section{María Elena Aguilar, María del Rosario Patricia Ledésma-Ramírez, José Manuel Mier-Odriozola}

INER Ismael Cosío Villegas

RESUMEN. Introducción: Malformación esternal (Lloyert A, 2015) más frecuente. Incidencia: 1:400 r.n, hombremujer 4:1, cartílagos costales inferiores, esternón y apéndice xifoides ocasionan una depresión. Ravitch, Welch y Nuss corrigieron quirúrgicamente el defecto. Disnea, lipotimias, palpitaciones y dolor (Kelly, 2008). Objetivo: Presentamos el caso de un paciente de 12 años que ingresó al INER con historia de síncope desde los 10 años, opresión torácica y dolor punzante. Material: Tórax excavatum asimétrico, índice de Haller de 3.5 con compresión del corazón. Método: Se rea- lizó técnica de Ravitch modificada, se disecaron las uniones costocondrales 7, 8, 9 y 10 colocando clips y barra de titanio. Un año después se retiró la barra de titanio. Resultado: Asintomático, no ha vuelto a presentar síncope, electrocardiograma actual. Conclusiones: Cuadro clínico más florido en adolescentes (Lucenik, 2015). La cirugía libera la opresión sobre el corazón y pulmón, mejorando calidad de vida (Velarde, 2013).

\section{Referencias}

1. Kelly RE. Pectus excavatum: historical background, clinical picture, and criteria for operation. Semin Pediatr Surg 2008;17:181-193.

2. Lloyert AFJ. Morphologic assesment of thoracic deformities for the preoperative evaluation of pectus excavatum by magnetic resonance imaging. Chest 2015;25:785-791.

3. López M, Zavaleta-Alfaro RVJ. Corrección del pectus excavatum por via extrapleural sin toracoscopio, en un paciente con cirugías toráxicas previas. Rev Med Hered 2013;24:226-230.

4. Lucenik MJ. Surgical repair of recurrent pectus excavatum in adults and adolescents. Rozhl Chir 2015;94:111-116.

5. Velarde JS. Calidad de vida y satisfacción postquirúrgica en pacientes pediatricos operados de pectus excavatum mediante técnica de Nuss. Rev Chil Pediatr 2013;84:166-176.

\section{Utilidad de la pirfenidona y colágena polivinilpirrolidona en la cicatrización traqueal experimental}

Mariana Silva-Martínez, J. Raúl Olmos-Zúñiga, Rogelio Jasso-Victoria, Matilde Baltazares-Lipp,

Claudia Hernández-Jiménez, Ivette Buendía-Roldan,

Samantha Rodríguez-Bastidas

INER Ismael Cosío Villegas

RESUMEN. La estenosis traqueal (ET) es una fibrosis originada por una inflamación prolongada, incremento en la expresión del factor de crecimiento transformante beta 1 (TGF- $\beta 1)$ y de- 
posición de colágena (DC). Se tratan con procedimientos endoscópicos y quirúrgicos, solos o en combinación con la aplicación de moduladores de la cicatrización (MDC); sin embargo, no se ha logrado evitar la reestenosis, por lo que es de interés buscar MDC que la eviten. La pirfenidona (PIRFE) y colágeno polivinilpirrolidona (CPVP) disminuyen la fibrosis por lo que su uso poscirugía podría evitar las ET. Objetivo: Determinar el efecto de la administración de PIRFE (VO) por cuatro semanas y la aplicación tópica de una dosis de CPVP sobre los cambios macroscópicos, microscópicos, expresión de TGF- $\beta 1$ y DC en cicatrices traqueales de ratas con resección y anastomosis terminoterminal de tráquea cervical (traqueoplastía). Material y métodos: Cincuenta ratas Wistar con traqueoplastía cervical, divididas en 5 grupos $(n=10)$ fueron tratadas con: grupo I: SSF, grupo II: CPVP, grupo III: mitomicina $\mathrm{C}$, grupo IV: $20 \mathrm{mg} / \mathrm{kg}$ PIRFE y grupo V: $40 \mathrm{mg}$ / kg PIRFE. Se valoró la cicatrización macroscópica y microscópica, expresión de TGF- $\beta 1$ y DC. Resultados: Los animales tratados con CPVP y PIRFE desarrollaron menor estenosis, inflamación y fibrosis que los otros grupos de estudio $(\mathrm{p}<0.05$ Kruskall Wallis) y menor expresión de TGF- $\beta 1$ y DC que el grupo I $(\mathrm{p}<0.05$ ANDEVA, Tukey). Conclusión: La CPVP y la PIRFE disminuyen la inflamación, fibrosis, expresión de TGF- $\beta 1$ y deposición de colágena en la cicatriz postraqueoplastía de ratas.

\section{Perfil psicológico de tutores de niños con hipoacusia bilateral profunda precandidatos a implante coclear}

\section{Eryka del Carmen Urdapilleta- Herrera, * Jimena Patricia Ruiz- Juárez,‡ Adriana Gabriela Lara-Rivas* \\ *INER Ismael Cosío Villegas; ¥UNAM}

RESUMEN. La hipoacusia bilateral profunda es un padecimiento relativamente común en países en desarrollo, el acceso a educación, a servicios de salud, entre otros, constituye factores de riesgo. El implante coclear es una alternativa importantísima en la rehabilitación. Las guías internacionales exigen diversos criterios para la colocación del implante, sin embargo, no siempre pueden ser cubiertos pues la exigencia es muy alta en términos de características psicológicas no aplicables a países como México. Objetivo: Explorar las características psicológicas de los tutores de niños con hipoacusia que son precandidatos a implante coclear. Material y métodos: 55 parejas de papás evaluadas con amplia batería psicológica. Resultados: Padres jóvenes < 30 años, $77 \%$ con preparatoria estudiada, inteligencia debajo del promedio y ansiedad y depresión leve y moderada. Conclusión: La toma de decisiones para el implante coclear debe considerar las condiciones en que el niño y sus padres se desarrollan, las oportunidades culturales y el contexto emocional de este padecimiento para ofrecer un tratamiento integral y ajustar los criterios de acuerdo con el tipo de población.

\section{Sobrecarga emocional del cuidador primario de pacientes con cáncer de pulmón}

Adriana Gabriela Lara-Rivas, Eryka del C. Urdapilleta-Herrera

INER Ismael Cosío Villegas

RESUMEN. Introducción: Los cuidadores primarios $(\mathrm{CP})$ de pacientes con cáncer de pulmón $(\mathrm{CaP})$, reportan mayores enfermedades físicas y mentales que en la población en general. El CP se caracteriza por tener un vínculo afectivo y no recibe remuneración económica por sus cuidados, por lo regular es un miembro de la familia. Objetivo: Describir la sobrecarga emocional en $\mathrm{CP}$ de pacientes con $\mathrm{CaP}$ en el INER. Material y métodos: Se evaluaron a $86 \mathrm{CP}$ que acompañan al paciente ambulatorio que asiste a su tratamiento de quimioterapias y en la consulta externa de oncología del INER, con los inventarios de ansiedad y depresión de Beck y con la escala de sobrecarga del cuidador Zarit.
Resultado: Se evaluó la sintomatología de ansiedad y depresión de 86 CP mayormente mujeres e hijas de los enfermos. Se obtuvo que las mujeres cuidadoras presentaron más sintomatología depresiva y de ansiedad en comparación con los cuidadores hombres: 11 vs. 8 y 11 vs. $7, \mathrm{p}=$ $0.48, \mathrm{p}=0.23$, respectivamente. Respecto a la sobrecarga, las mujeres reportaron tener significativamente $(\mathrm{p}<0.05)$ más sobrecarga emocional en comparación con los cuidadores hombres. Conclusiones: Otros estudios coinciden con estos resultados, dado que las mujeres son más vulnerables a la sintomatología y especialmente las mujeres que cuidan a un paciente con cáncer. Este estudio tuvo la peculiaridad de ser en su mayoría hijas, lo cual podría sumar componentes que hacen de esta tarea una actividad dolorosa emocionalmente y con gran sobrecarga, al jugar diferentes roles que exigen enormes esfuerzos.

\section{Necesidades de apoyo psicológico del paciente con cáncer de pulmón}

\section{David Enrique González}

INER Ismael Cosío Villegas

RESUMEN. Introducción: La atención psicológica para las personas que viven con cáncer de pulmón es de suma importancia. La identificación y respuesta a las necesidades de apoyo representan un requisito para la atención oportuna de síntomas, efectos secundarios del tratamiento, adopción de estilos de afrontamiento adecuados y mejora en la toma de decisiones, para con ello disminuir el sufrimiento, mejorar la calidad de vida y la satisfacción con la atención de los servicios de salud. Objetivo: Identificar las necesidades de apoyo psicológico de pacientes con cáncer de pulmón que reciben tratamiento médico. Métodos: Estudio descriptivo, prospectivo en pacientes con diagnóstico de cáncer de pulmón atendidos entre julio de 2015 y julio de 2016. Se registraron las necesidades de apoyo en las notas de psicología al término de cada sesión. Se elaboraron siete categorías: malestar emocional, manejo de malas noticias, adherencia al tratamiento médico, la 
muerte, control de síntomas, comunicación médico-paciente y problemas familiares. Resultados: Se atendieron en consulta individual o familiar a 288 pacientes, la mayoría fueron mujeres (64\%), el promedio de edad fue de 62 años. De un total de 534 intervenciones de apoyo psicológico, $37.6 \%$ correspondieron a la categoría malestar emocional, $16.3 \%$ adherencia al tratamiento médico, $13.9 \%$ la muerte, $10.7 \%$ manejo de malas noticias, $9.9 \%$ control de síntomas, $8 \%$ comunicación médico-paciente y $3.6 \%$ problemas familiares. Conclusiones: Las necesidades de apoyo psicológico de esta población se concentran en el malestar emocional, mientras que los porcentajes en las categorías: adherencia al tratamiento médico, la muerte, manejo de malas noticias y control de síntomas se pueden deber a la mejoría en los tratamientos para el cáncer y a una mayor sobrevida de los pacientes, lo que a su vez impacta en la comunicación médico-paciente, los problemas familiares pasaron a segundo plano.

\section{Estenosis traqueal: correlación tomográfica con la pruebas de función respiratorias}

Enrique Guzmán-de Alba, Juan Alberto Berrios-Mejía, Lya Edith Pensado-Piedra, Laura Graciela Gochicoa-Rangel

INER Ismael Cosío Villegas

RESUMEN. La estenosis traqueal posintubación es un problema clínico causado por la isquemia y necrosis regional de la vía aérea, que condiciona una reacción cicatricial con reducción del diámetro de su luz. El seguimiento de pacientes con estenosis traqueal y la decisión de realizar intervenciones terapéuticas se realizan frecuentemente tomando en cuenta los síntomas del paciente. Por el momento no se cuenta con alguna otra herramienta para la toma de este tipo de decisiones. Thomas Horan et al. intentaron determinar la utilidad de la oscilometría para la detección y seguimiento de la estenosis traqueal, incluyó a 10 participantes a quienes se les realizó oscilometría de impulso y espirometría forzada pre y posbroncodilatador, así como broncoscopia diagnóstica y terapéutica. Los resultados fueron una fuerte correlación (r) entre la frecuencia de resonancia y el diámetro traqueal, medido por broncoscopia, con una r entre -0.91 y 0.81 , resistencia a 5 Hertz con una $\mathrm{r}-0.87$ a 0.69 , para FVC y FEV no hubo correlación significativa, no se reportan datos para resistencia a 20 Hertz. Planteamiento del problema: ¿Existe correlación entre el grado de estenosis traqueal posintubación medida mediante tomografía computarizada y las pruebas de función pulmonar? Hipótesis: Existe una correlación entre el grado de estenosis traqueal medido mediante tomografía computarizada, el flujo pico espirométrico y la resistencia a $20 \mathrm{~Hz}$ en pacientes con estenosis traqueal. Justificación: El presente estudio permitirá conocer la correlación y concordancia que existe entre el grado de afectación estructural evaluado por tomografía con una escala estandarizada, espirometría y oscilometría de impulso, que será de gran utilidad para definir los mejores parámetros para el diagnóstico y seguimiento de los pacientes con estenosis traqueal. Objetivo general: Evaluar la correlación entre el grado de estenosis traqueal posintubación medida por tomografía de vía aérea y las medidas espirométricas y la resistencia por oscilometría de impulso durante el seguimiento de los pacientes con estenosis traqueal. Método: Estudio observacional, prospectivo, transversal realizado en el Instituto Nacional de Enfermedades Respiratorias, Ciudad de México. Período de estudio: del 1 de enero 2014 al 30 diciembre de 2015. Selección de la muestra no probabilística que cumplieran los criterios de inclusión y exclusión a los participantes. Criterios de inclusión: paciente con estenosis traqueal posintubación confirmada, mayor de 18 años, consentimiento informado por escrito. Criterios de exclusión: estenosis traqueal compleja definida como dos más niveles de estenosis traqueal, componente dinámico de la estenosis con traqueomalasia, antecedente de EPOC o asma, portador de traqueostomía, sujeto sano que no pueda realizar maniobras aceptables de las pruebas de función respiratoria, com- plicaciones pulmonares como neumonía o derrame pleural. Descripción: se le realizó TAC de vía aérea con reconstrucciones coronales y sagitales para evaluar el área en el sitio de menor luz y en la tráquea inmediatamente distal a la estenosis donde se evidenciara normal. Además se realizó espirometría simple y oscilometría de impulso. Análisis estadístico: el grado de afectación anatómica obtenido de la TAC se correlacionó con las principales variables de las PFR mientras que el acuerdo entre los parámetros se analizó de manera gráfica y estadística usando el coeficiente de correlación de Spearman, las diferencias se consideraron significativas con el valor de $\mathrm{p}$ se consideró significativo < 0.05. Los programas empleados para el estudio fueron IBW SPSS versión 20.0 y CurveExpert versión 1.4. Resultados: Se reclutaron un total de 24 participantes, de los cuales 15 (62.5\%) eran del sexo masculino, con una edad media de 35 años. Para el flujo pico espiratorio medido en porcentajes se encontró una media de 48.2 \pm 24.4 , con un coeficiente de correlación negativo de 0.56 , con una $\mathrm{p}$ significativa de 0.004 , asimismo para los valores en litro encontramos una media de $4.051 \pm$ 2.451 , con un coeficiente de correlación negativo de 0.56 , y p de 0.001. Para la resistencia $5 \mathrm{~Hz}$ se encontró una media de $0.84 \mathrm{kPa} / \mathrm{L} / \mathrm{s} \pm 0.39$, con un coeficiente de correlación positivo de 0.61 , y una p significativa de 0.001 , para la resistencia $20 \mathrm{~Hz}$ se encontró una media de 0.43 $\mathrm{kPa} / \mathrm{L} / \mathrm{s} \pm 0.22$, con valor de correlación de 0.63 , con una p de 0.08. Conclusiones: El estudio demuestra que existe una buena correlación negativa entre el flujo espiratorio pico y el grado de obstrucción medido por tomografía. Así como una buena correlación entre la oscilometría de impulso a $5 \mathrm{~Hz}$ y la obstrucción. La oscilometría de impulso y el flujo pico espiratorio son los métodos preferentes para el seguimiento de los pacientes con estenosis traqueal post intubación.

\section{Reducción de la recurrencia de estenosis traqueal posoperatoria con el empleo de colágeno polivinilpirrolidona}


Marco Antonio Iñiguez, Juan Alberto Berríos-Mejía, Martín Ibarra, Ixchel Carranza, Raúl Olmos-Zúñiga, Rogelio Jasso-Victoria

INER Ismael Cosío Villegas

RESUMEN. La resección y anastomosis traqueal es el estándar de tratamiento de la estenosis traqueal. La recurrencia oscila del 5-20\%, principalmente resultado de la formación de fibrosis. La colágena polivinilpirrolidona reduce la formación de las fibras de colágena. Objetivo: Evaluar la utilidad de la colágena polivinilpirrolidona adyuvante a la resección y anastomosis traqueal para reducir la recurrencia posquirúrgica. Método: Estudio observacional, prospectivo, longitudinal realizado en el Instituto Nacional de Enfermedades Respiratorias, Ciudad de México, en el período del 1 de enero del 2014 al 31 de diciembre del 2015. Selección de la muestra no probabilística, se seleccionaron dos grupos de forma prospectiva, en el grupo control se realizó la resección traqueal y la anastomosis terminoterminal con puntos de vycril 3.0 (VICRYL ${ }^{\circledR}$, (polyglactin 910, Ethicon ${ }^{\circledR}$ ), New Jersey USA), al grupo de casos se agregó la colocación de una esponja colágena-polivinilpirrolidona 2.2 $\mathrm{mg}$ (Fibroquel esponja, Aspidpharma S.A. de C.V.). El seguimiento fue clínico, con pruebas de función respiratorias y broncoscopia ante los síntomas de recurrencia de estenosis traqueal. Análisis estadístico: Se empleó un modelo de regresión logística para variables dependientes, se consideró significativa una $\mathrm{p}$ con un valor $<0.05$. El análisis se realizó a través IBW SPSS versión 20.0. Resultados: Se reclutaron 78 participantes, 39 del grupo de control y 39 del grupo de casos (fibroquel), la media de edad fue 35.5 años $( \pm 13.2$ años), sexo masculino en el 70.5\% (55/78), la reestenosis se presentó en el 11\% (9/78), los grupos fueron comparables en relación con las variables predictoras de reestenosis. Encontramos que en el grupo que se empleó fibroquel la recurrencia fue de $2.6 \%$ (1/39), en el grupo de control $20.5 \%$ (8/39), con una OR 0.1 (IC 95\%: 0.01-0.8) $\mathrm{p}=0.013$. Conclusión: La administración de colágeno polivinilpirrolidona después de la anastomosis traqueal reduce la recurrencia de estenosis posoperatoria. Se requiere la realización de un estudio prospectivo aleatorizado para confirmar nuestros resultados.

\section{Importancia de diagnóstico de enfermedad digestiva como causa de neumonía recurrente}

María del Carmen Castillo-Villatoro, Mayda Gabriela Sánchez-Urueta, Margarita Salcedo-Chávez, Jerico Hernández-Buchelli, Victoria FalcónSolís, Sebastián Inzunza-Saldaña

INER Ismael Cosío Villegas

RESUMEN. La participación de la $\mathrm{HH}$ en el RGE ha sido tema de debate por mucho tiempo. La prevalencia de $\mathrm{HH}$ en niños no es conocida con seguridad. De acuerdo con algunos estudios, la $\mathrm{HH}$ no es común en los niños, aunque existen diferentes autores que han reportado una incidencia entre el 6.3 y $41 \%$ en niños neurológicamente normales. Se presenta clínicamente en un $8.5 \%$ de los pacientes con tos e hiperreactividad bronquial. Femenina de un año un mes de edad, con antecedente de ser producto de la gesta 1 , cursando con embarazo normoevolutivo, obtenida por cesárea indicada por oligohidramnios, Apgar 8/9, peso y talla adecuados; Capurro 41 SDG. Hospitalización al nacimiento por 10 días por hiperbilirrubinemia multifactorial tratada con fototerapia, tamiz metabólico realizado, auditivo negado, caída del cordón a los 60 días. Personales patológicos: Hospitalizada en siete ocasiones previas en otra institución: primera al nacimiento referido, seis más por cuadros de neumonía, en la quinta ocasión por tres meses, siendo meritorio manejo en UTIP, con VM por tres semanas, encontrando RGE grado III, se realizó funduplicatura; último cuadro a los 10 meses. Comentando cursaba en dichos cuadros con sibilancias, siendo tratada siempre con MNS. Se refiere sólo de datos positivos para reflujo posición de Sandifer. Padecimiento actual: Inicia dos días previos con accesos de tos productiva, no disneizante, rubicundizante, no emetizante, acompañado de rinorrea hialina, agregándose a las 24 horas incremento en patrón respiratorio, por lo cual acuden para su valoración, EF inicial se encuentran abundante rinorrea hialina, faringe discretamente hiperémica, tórax con dificultad respiratoria caracterizada por taquipnea, tiraje intercostal leve, a la auscultación presencia de disminución de murmullo vesicular, con sibilancias espiratorias. Resto de EF sin alteraciones. Radiografía de tórax sin hallazgos positivos que comentar. Saturando $89 \%$, por lo cual se decide su ingreso hospitalario con Dx de silbante no atópico, neumonía recurrente, PO funduplicatura. Durante su estancia se realizó gammagrama esofágico: RGE grado III, vaciamiento gástrico normal. TAC por abordaje de neumonía recurrente: se observa a nivel de mediastino imagen retrocardíaca, redondeada, heterogénea, que al administrar contraste hidrosoluble por VO se confirma hernia hiatal. Se envía a Servicio de Gastroenterología para su corrección. La tasa de falla de la cirugía antirreflujo primaria varía entre 3 y $30 \%$ dependiendo de la experiencia quirúrgica del centro. Un grupo de pacientes operados manifestará síntomas recurrentes o persistentes después de la intervención. Diversos estudios han mostrado que la falla de la primera cirugía antirreflujo es consecuencia de características intrínsecas del paciente, así como de factores ambientales que causan estrés en el sitio quirúrgico y problemas técnicos de la intervención. Debido al aumento en el número de funduplicaturas primarias practicadas, las cirugías antirreflujo fallidas son un hallazgo cada vez más común siendo la reintervención necesaria en el 3 al 6\% de los casos. Las etiologías más comunes de la falla son la recurrencia de hernia hiatal y la disrupción de la funduplicatura, que combinadas representan entre el 50 y el $65 \%$. 